\title{
Analysis of Airborne Optical and Thermal Imagery for Detection of Water Stress Symptoms
}

\author{
Max Gerhards ${ }^{1,2, *(1)}$, Martin Schlerf ${ }^{1}$, Uwe Rascher ${ }^{3}$ (i), Thomas Udelhoven ${ }^{2}$, \\ Radoslaw Juszczak ${ }^{4}$, Giorgio Alberti ${ }^{5}$, Franco Miglietta ${ }^{6}$ (iD) and Yoshio Inoue ${ }^{7}$ \\ 1 Luxembourg Institute of Science and Technology (LIST), Environmental Research and Innovation (ERIN) \\ Department, 41 Rue du Brill, L-4422 Belvaux, Luxembourg; martin.schlerf@list.lu \\ 2 Remote Sensing \& Geoinformatics Department, Behringstrasse, Faculty of Geography and Geosciences, \\ University of Trier, D-54296 Trier, Germany; udelhoven@uni-trier.de \\ 3 Forschungszentrum Jülich, Institute of Bio- and Geosciences, IBG-2: Plant Sciences, 52425 Jülich, Germany; \\ u.rascher@fz-juelich.de \\ 4 Department of Meteorology, Poznan University of Life Sciences, 60649 Poznan, Poland; \\ radjusz@up.poznan.pl \\ 5 Department of Agricultural, Food, Environmental and Animal Sciences, University of Udine, \\ 33100 Udine, Italy; giorgio.alberti@uniud.it \\ 6 National Research Council, Institute of Biometeorology, 50145 Firenze, Italy; f.miglietta@ibimet.cnr.it \\ 7 Research Center for Advanced Science and Technology, University of Tokyo, Tokyo 153-8904, Japan; \\ yinoue@affrc.go.jp \\ * Correspondence: gerhardsm@uni-trier.de; Tel.: +49-651-201-4596
}

Received: 13 June 2018; Accepted: 16 July 2018; Published: 19 July 2018

Abstract: High-resolution airborne thermal infrared (TIR) together with sun-induced fluorescence (SIF) and hyperspectral optical images (visible, near- and shortwave infrared; VNIR/SWIR) were jointly acquired over an experimental site. The objective of this study was to evaluate the potential of these state-of-the-art remote sensing techniques for detecting symptoms similar to those occurring during water stress (hereinafter referred to as 'water stress symptoms') at airborne level. Flights with two camera systems (Telops Hyper-Cam LW, Specim HyPlant) took place during 11th and 12th June 2014 in Latisana, Italy over a commercial grass (Festuca arundinacea and Poa pratense) farm with plots that were treated with an anti-transpirant agent (Vapor Gard ${ }^{\circledR} ; \mathrm{VG}$ ) and a highly reflective powder (kaolin; KA). Both agents affect energy balance of the vegetation by reducing transpiration and thus reducing latent heat dissipation (VG) and by increasing albedo, i.e., decreasing energy absorption (KA). Concurrent in situ meteorological data from an on-site weather station, surface temperature and chamber flux measurements were obtained. Image data were processed to orthorectified maps of TIR indices (surface temperature $\left(T_{s}\right)$, Crop Water Stress Index (CWSI)), SIF indices $\left(\mathrm{F}_{687}, \mathrm{~F}_{780}\right)$ and VNIR/SWIR indices (photochemical reflectance index (PRI), normalised difference vegetation index (NDVI), moisture stress index (MSI), etc.). A linear mixed effects model that respects the nested structure of the experimental setup was employed to analyse treatment effects on the remote sensing parameters. Airborne $T_{s}$ were in good agreement $(\Delta T<0.35 \mathrm{~K})$ compared to in situ $T_{S}$ measurements. Maps and boxplots of TIR-based indices show diurnal changes: $T_{S}$ was lowest in the early morning, increased by $6 \mathrm{~K}$ up to late morning as a consequence of increasing net radiation and air temperature $\left(T_{a i r}\right)$ and remained stable towards noon due to the compensatory cooling effect of increased plant transpiration; this was also confirmed by the chamber measurements. In the early morning, VG treated plots revealed significantly higher $T_{s}$ compared to control (CR) plots $(p=0.01)$, while SIF indices showed no significant difference $(p=1.00)$ at any of the overpasses. A comparative assessment of the spectral domains regarding their capabilities for water stress detection was limited due to: (i) synchronously overpasses of the two airborne sensors were not feasible, and (ii) instead of a real water stress occurrence only water stress symptoms were simulated by the chemical agents. Nevertheless, the results of the study show that the polymer di-1-p-menthene had an anti-transpiring 
effect on the plant while photosynthetic efficiency of light reactions remained unaffected. VNIR/SWIR indices as well as SIF indices were highly sensitive to KA, because of an overall increase in spectral reflectance and thus a reduced absorbed energy. On the contrary, the TIR domain was highly sensitive to subtle changes in the temperature regime as induced by VG and KA, whereas VNIR/SWIR and SIF domain were less affected by VG treatment. The benefit of a multi-sensor approach is not only to provide useful information about actual plant status but also on the causes of biophysical, physiological and photochemical changes.

Keywords: thermal infrared; water stress detection; airborne; vegetation indices; sun-induced fluorescence; high performance imaging spectroscopy; hyperspectral; photosynthesis

\section{Introduction}

In the context of climate change and an increasing global water scarcity, water deficit stress (normally shortened to water stress) is one of the most critical abiotic stressors to plant growth. In order to increase the quantity and quality of food production using a reduced amount of water, the detection and quantification of plant stresses is of major interest for agriculture in general and precision farming in particular [1]. Remote sensing provides powerful tools in different spectral domains for spatiotemporal monitoring of water stress [2].

Plant response to water stress is expressed by a variety of physiological changes (e.g., stomatal behaviour, and leaf water content), biophysical changes (energy balance, leaf and canopy structure, and biomass and yield) as well as photochemical processes [3-5]. Accordingly, various attempts have been made to detect these changes using remotely sensed signatures. To date, the main remote sensing imaging techniques for plant water stress detection are thermal imaging (TIR; 8-14 $\mu \mathrm{m}$ ), visible, near- and shortwave infrared reflectance (VNIR/SWIR; 0.4-2.5 $\mu \mathrm{m}$ ), and sun-induced fluorescence (SIF; 0.69 and $0.76 \mu \mathrm{m}$ ).

TIR imaging has been well studied for water stress detection, e.g., [6-8]. The underlying principle is that plant temperature rises with increasing water stress in comparison to a well-watered plant due to decreasing evaporative cooling through stomatal closing [9]. Since stomatal closure is one of the first responses to water stress, plant temperature as measured by TIR sensors can be used to detect water stress pre-visually $[7,10,11]$. Plant temperature, however, is not solely governed by the plant water supply but also by the actual micro-meteorological conditions (i.e., solar radiation, wind speed, leaf boundary layer resistance and vapour pressure deficit (VPD)). Therefore, as an alternative to using absolute temperature, several temperature-based indices were developed over the last few decades with the aim of compensating for varying meteorological conditions. For example, the prominent Crop Water Stress Index (CWSI) [12] by means of artificial references does not require any additional meteorological measurements to be calculated. The usefulness of temperature-based indices has recently been demonstrated in several airborne studies [13-16]. Currently, the main limitation of all temperature-based (i.e., absolute temperature and temperature-based indices) approaches arises from the use of broadband infrared cameras with erroneous temperature retrieval by assuming an emissivity value that is pre-determined (e.g., $\varepsilon=0.97$ for vegetation) and constant over the spectral range from 8 to $14 \mu \mathrm{m}$. For example, an error of $1 \%$ emissivity results in an absolute temperature error of $1 \mathrm{~K}$ [7]. However, very recently hyperspectral TIR airborne imagers such as Telops Hyper-Cam LW, Itres TASI-600, or Specim AisaOWL have become available. These devices allow for stable temperature and emissivity separation (TES) and very accurate temperature retrieval (i.e., $<0.5 \mathrm{~K}$ ) by measuring the emitted radiation in many narrow bands [17]. The importance of airborne (hyperspectral) TIR remote sensing lies in the possibility of bridging the gap between ground-based thermography e.g., $[11,18]$ and proposed satellite missions, such as ECOSTRESS (Ecosystem Spaceborne Thermal Radiometer 
Experiment on Space Station, [19]), HyspIRI (Hyperspectral Infrared Imager, [20]) or the hyperspectral mission concept HiTeSEM (High-resolution Temperature and Spectral Emissivity Mapping, [21]).

In the VNIR/SWIR domain, various spectral vegetation indices (VI) have been developed, each for a specific purpose such as canopy water content (MSI; [22]), greenness or fractional vegetation cover (NDVI; [23]), or photosynthetic activity (PRI; [24]). As these plant parameters are somehow related to plant water status (e.g., photosynthetic activity, chlorophyll and water content may decrease under water stress conditions $[3,25,26])$, these VIs may serve as indicators of water stress [13-15]. Among the large variety of available indices, the PRI (photochemical reflectance index; [24]) is related to non-photochemical heat dissipation, which may be linked to water availability and photosynthetic efficiency. In fact, PRI is heavily influenced by canopy effects and pigment content, but Suarez et al. [27-29] suggest that the use of PRI in combination with radiative transfer modelling, accounting for these effects, can effectively provide very good means for monitoring water stress in crops and natural vegetation at airborne level. However, the ability of the PRI to be used for water stress detection is not conclusive at a small-scale experimental ground and airborne level $[13,14,18]$.

At the same time, remote sensing of sun-induced fluorescence (SIF) has become increasingly popular over the last decade with a variety of studies ranging from ground-based experiments to airborne campaigns and even towards satellite missions (see Meroni et al. [30] for a comprehensive review). In principle, radiative energy absorbed by leaf chlorophyll is processed along three competing pathways: (i) conversion of photosynthetic active radiation (PAR) to sugars through photosynthesis, (ii) the re-emission of non-used energy through chlorophyll fluorescence or (iii) dissipation of heat [31]. Hence, these three processes are in competition with each other; variation in one of the processes affects the others [32]. For example, plant photosynthetic efficiency is reduced under environmental stress conditions (i.e., water or nutrient shortage, heat stress, and other types of stress) due to plants protective mechanisms (e.g., leaf rolling reduces the plants surface and therefore the PAR (Photosynthetically Active Radiation) absorbance; stomatal closure reduces water loss and $\mathrm{CO}_{2}$ uptake). In this context, SIF is expected to be a direct indicator of photosynthetic efficiency and plant stress, although further studies are needed to establish a consistent basis for robust assessment $[31,33]$. The HyPlant sensor facilitates sub-nanometre airborne acquisitions from the red $(0.68 \mu \mathrm{m})$ towards the far red $(0.78 \mu \mathrm{m})$ spectral range. Current experiments using the HyPlant sensor demonstrated the capability of quantitative plant stress detection at airborne level using both red and far red chlorophyll fluorescence peaks [32].

These preceding studies suggest that plant water stress symptoms may be detectable by means of the three approaches (TIR temperature indices, VNIR/SWIR VIs and SIF indices). However, since they are based on different models and physiological processes, the sensitivity and suitability of these approaches may vary depending on the target and environmental conditions. Therefore, to examine the detectability of water stress symptoms by the three approaches, we conducted a field-scale experiment specifically designed to tentatively evaluate the potential of state-of-the-art remote sensing at airborne level. Hyper-Cam LW as well as HyPlant sensors were flown over a commercial grass farm. Water stress symptoms were simulated by treating grass surfaces with two different chemical agents and comparing them to untreated Control (CR) plots.

The first agent, the anti-transpirant Vapor Gard ${ }^{\circledR}$ (VG; Miller Chemical and Fertilizer, Hanover, PA 17331, USA), is composed of di-1-p-menthene, a natural terpene polymer. The emulsion surrounds the leaves with a thin film and is supposed to reduce the plants water transpiration by limiting stomatal conductance. Thus, VG is recommended for farming to reduce water loss and prevent water stress in times of limited water availability [34-36]. Because of decreasing stomatal conductance, transpiration is also reduced and consequently plant surface temperature is expected to be significantly increased in comparison to a CR plot. Furthermore, VG does not only have an effect on the permeability of water but also reduces $\mathrm{CO}_{2}$ uptake rates [37]. The second agent, kaolin (KA) is a highly reflective white powder and can be dissolved in water and sprayed on plants. The white color of KA increases the albedo of the plant surface and therefore reduces the absorbed light energy (APAR). 
Thus, we assume that VG treated plants (in comparison to CR plants) have: (i) decreased transpiration, (ii) increased leaf temperature, and (iii) decreased photosynthetic activity, while keeping relatively high leaf water and chlorophyll content (in case of enough soil moisture). We assume further that KA treated plants (in comparison to CR plants) have: (iv) decreased absorbed radiation resulting in decreased transpiration under energy-limited conditions (in case of sufficient soil water), but also (v) little change in stomatal conductance, leaf temperature, photosynthetic efficiency, leaf water and chlorophyll content.

However, it is still unknown how well they allow the detection of plant water stress symptoms at airborne level. Thus, the overall aim of this study was to evaluate the capability of selected TIR and VNIR/SWIR hyperspectral remote sensing indices, as well as SIF remote sensing for detection of plant water stress symptoms. The specific objectives were: (i) examining if different temperature-based indices (e.g., CWSI, $T_{S}, T_{s}-T_{\text {air }}$ ), traditional VNIR/SWIR indices (e.g., PRI, NDVI, MSI), and SIF indices reveal differences over grass plots treated with chemical agents (VG and KA); (ii) an assessment of why the different indices may or may not have changed from treatments with respect to the underlying physiological processes; (iii) specifically examining diurnal changes in temperature-based index values regarding different treatments.

\section{Materials and Methods}

\subsection{Experimental Design}

In June 2014, a field-scale experiment was conducted on a 2 ha commercial grass (Festuca arundinacea and Poa pratense at the ratio of $90 \%$ to $10 \%$, respectively) farm near to Latisana, northeast Italy $\left(45^{\circ} 46^{\prime} 46.1^{\prime \prime} \mathrm{N}, 13^{\circ} 00^{\prime} 50.5^{\prime \prime} \mathrm{E}\right)$ (Figure 1). The grass was cut at a height of 30-50 mm. All plots were well watered with an irrigation of $40 \mathrm{~mm}$ per week. The soil texture was silty clay. Plant characteristics were modified by two chemical treatments (VG and KA) to simulate symptoms similar to those occurring during water stress. A replicated block design with three replicates was adopted (Figure 1). The average plot size was $12 \times 9 \mathrm{~m}$ for CR and VG and $9 \times 9 \mathrm{~m}$ for KA plots. In the evening of 10 th June 2014 , tagged plots were treated by $15 \mathrm{~L}$ of an emulsion of $3 \% \mathrm{VG}$ and $15 \mathrm{~L}$ of $60 \mathrm{~g} \mathrm{~L}^{-1} \mathrm{KA}$.

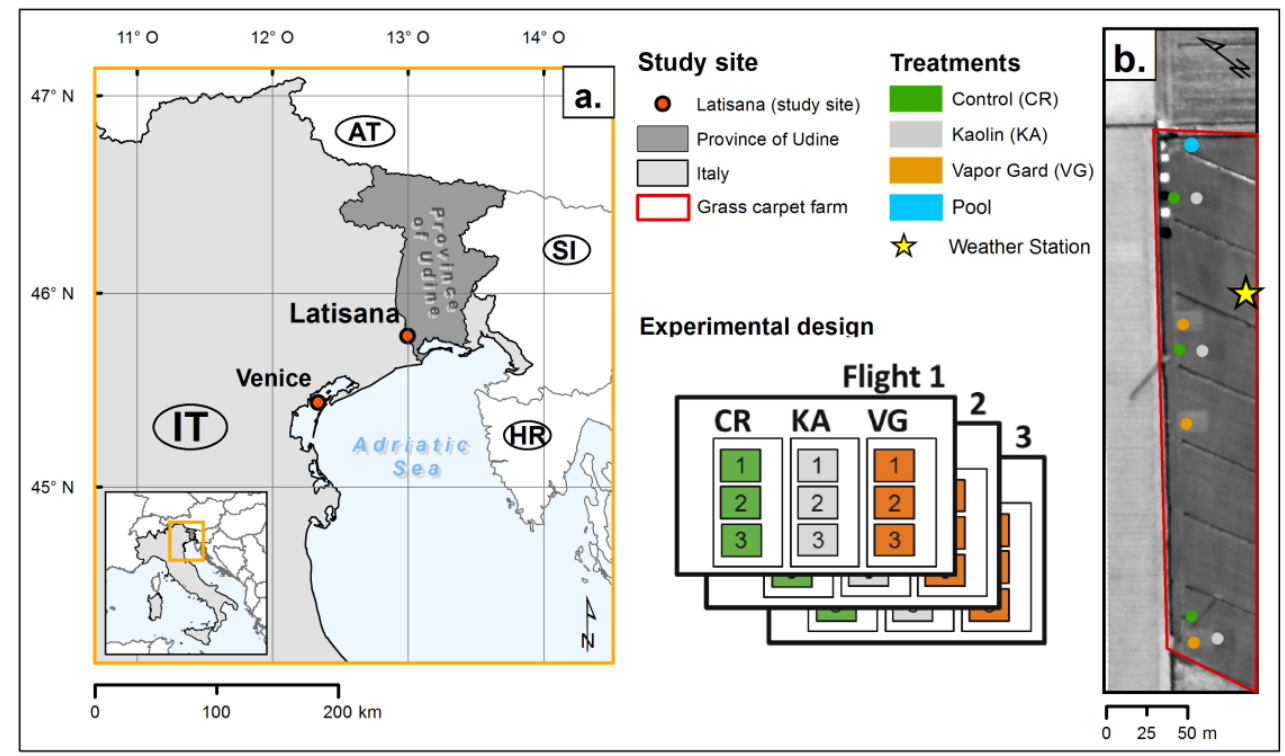

Figure 1. Overview of the study site with the experimental setup. The study site was located in northeastern Italy near the town of Latisana (a). (b) shows the locations of the experimental plots, pool and weather station. A scheme of the experimental design is presented in the legend. 
During the experiment, airborne and in situ data were collected. Airborne data were acquired with two camera systems (Telops Hyper-Cam LW, Specim HyPlant) during 11th and 12th June 2014. Concurrent in situ meteorological data from an on-site weather station, surface temperature and chamber flux measurements were obtained.

\subsection{Airborne Images}

\subsubsection{Overview}

The airborne flight campaign was organised within the framework of an annual FLEX-EU campaign. The experimental site was overpassed three times during 11th and 12th June from both Hyper-Cam LW and HyPlant airborne sensor, respectively. TIR images were acquired using Telops Hyper-Cam LW on 11th June 2014 in the early morning at 09:18, late morning at 10:48 and at midday near solar noon at 12:51 (all Central Europe Solar Time, CEST). Unfortunately, synchronised overpasses of both airborne sensor were not possible. Thus, the nearest available three HyPlant imagery acquisitions were selected. The first flight occurred on 11th June at 14:52, whereas, second and third overpasses were performed one day later (12th June) at 12:02 and 13:40 (all CEST), respectively.

Hyper-Cam LW sensor was flown at a survey height of $1430 \mathrm{~m}$ above ground resulting in a ground sampling distance (GSD) of $0.5 \mathrm{~m}$ per pixel. HyPlant sensor was flown at $600 \mathrm{~m}$ height resulting in $1 \mathrm{~m}$ GSD. To obtain a consistent dataset, HyPlant images were co-registered to Telops Hyper-Cam LW spatial resolution $(0.5 \mathrm{~m})$. Nearest neighbour interpolation was used for resampling. Over each plot a circular region of interest (ROI, size: 32 pixels) was defined and the corresponding image values were extracted and stored in a database. The ROI were defined to be circular around the central pixel of each plot, in order to prevent any boundary effects. Each ROI covers a grass surface area of approximately $8 \mathrm{~m}^{2}$.

\subsubsection{Thermal Images}

TIR airborne data were recorded using a Hyper-Cam LW (Telops Inc., Québec City, Québec, Canada, www.telops.com) mounted on a customized airborne platform. The base instrument is a FTIR (Fourier transformed infrared) spectrometer consisting of a $320 \times 256$ pixel MCT (mercury cadmium telluride) focal plane array (FPA) detector with up to $0.25 \mathrm{~cm}^{-1}$ spectral resolution in the spectral range of 7.7 to $11.5 \mu \mathrm{m}\left(1298.7\right.$ to $\left.869.6 \mathrm{~cm}^{-1}\right)$. The camera system is provided with two internal blackbodies with a known emissivity $(\varepsilon \geq 0.99)$ for radiometric calibration. The airborne platform combines the Image Motion Compensator (IMC) mirror, an Inertial Measurement Unit (IMU) consisting of GPS and Inertial Navigation System (INS), as well as a visible bore-sighted camera mounted on a base plate [17]. The IMC mirror compensates for airborne forward motion and guarantees gapless image acquisition. Furthermore, the IMC balances airborne pitch and roll, while the stabilization platform reduces airborne vibrations and airborne yaw. The IMU recordings enable ortho-rectification and geo-referencing of the collected data. TIR images were acquired with a spectral sampling distance of $6.65 \mathrm{~cm}^{-1}$ with $8 \mathrm{~cm}^{-1}$ FWHM (Full Width at Half Maximum) in the spectral domain from 878 to $1277 \mathrm{~cm}^{-1}$ resulting in 60 spectral bands.

In order to retrieve LST (Land Surface Temperature) from Hyper-Cam LW data cubes several radiometric and geometric processing steps were performed. First, raw interferograms were transformed to spectral radiances $\left(\mathrm{W} \mathrm{m}^{-2} \mathrm{sr}^{-1} \mathrm{~cm}^{-1}\right)$ using a Fourier transformation, followed by a two-point calibration based on the internal blackbodies with known temperature and emissivity $(\varepsilon \geq 0.99)$. This process was conducted using Telops Reveal calibrate software resulting in single image cubes in units of spectral radiance. Second, the single image cubes were orthorectified and geo-referenced using the information of the IMU, before they were mosaicked to single flight lines. This geometric correction was performed using Telops Airborne software. Third, the so-called "Blackbody Fit" approach [38] was performed to retrieve LST from spectral radiances. This simple approach needs a minimum of a priori knowledge to fit the measured spectral radiances of each pixel to a Planck-curve with a known temperature. Following Schlerf et al. [17] the fit was performed 
in the spectral range between $880 \mathrm{~cm}^{-1}(11.4 \mu \mathrm{m})$ and $912 \mathrm{~cm}^{-1}(11.0 \mu \mathrm{m})$ and with an assumed emissivity of $97 \%(\varepsilon=0.97)$, which is in good agreement with common findings about plant emissivity e.g., [18,39-41]. The best fit was then found by iteratively changing the temperature of the Planck-curve and using a non-linear least square curve fitting approach to assess the goodness of fit [42].

Any atmospheric distortions within the optical path (i.e., upwelling and downwelling radiance as well as transmittance) was neglected for the following reasons: (i) because of the low survey altitude, the atmosphere imposes limited effects on the recorded signal; (ii) the small-scale study site limited horizontal variations in atmospheric gas concentrations and (iii) only relative differences in temperature (i.e., temperature-based indices) were studied.

To validate the accuracy of LST retrieval, airborne temperature $\left(T_{\text {airborne }}\right)$ were compared to ground measured temperatures ( $T_{\text {ground }}$ ) of a water body. $T_{\text {ground }}$ was measured at the surface of a water filled pool (366 cm in diameter) along a profile (i.e., along the diameter of the pool) of five thermocouples. Thermocouples have a certificated accuracy (ISO 17025) of $0.5 \mathrm{~K} . T_{\text {airborne }}$ was extracted from corresponding TIR images as an average of four pixels within the pool.

Since absolute plant temperatures are very sensitive to rapidly changing meteorological conditions and therefore are not very suitable to detect water stress symptoms and diurnal changes, two additional temperature-based indices were calculated: (i) the difference between plant surface and air temperature $\left(T_{s}-T_{\text {air }}\right.$ ) based on the approach of Stress Degree Day (SDD) [43] and (ii) the in-scene Crop Water Stress Index (CWSI) approach following the idea of using artificial wet and dry reference surfaces [44]. CWSI was retrieved using the following equation:

$$
\text { CWSI }=\frac{T_{S}-T_{\text {wet }}}{T_{d r y}-T_{\text {wet }}}
$$

where $T_{S}$ is the plant surface temperature, $T_{\text {wet }}$ for the lower boundary of plant surface temperature, assuming a leaf with stomata fully open and a potential transpiration rate of $100 \%$ and $T_{d r y}$ is the upper boundary compared to a non-transpiring leaf with stomata completely closed. Since the fleece material artificial reference surfaces located next to the treatment plots turned out unsuitable for this study (i.e., wet reference surface was warmer than coolest $C R$ pixel and dry reference surface was up to $15 \mathrm{~K}$ warmer compared to the warmest pixel of the VG treatment), CWSI was determined by an empirical approach. The lower limit $\left(T_{\text {wet }}\right)$ was calculated using the coolest $5 \%$ of the CR treatment pixel [45], assuming that the CR plots were well watered. The upper boundary was calculated by adding $5 \mathrm{~K}$ to the current $T_{\text {air }}$ (i.e., $T_{d r y}=T_{\text {air }}+5 \mathrm{~K}$ ). This approach has been previously suggested by Meron et al. [46] and Cohen et al. [6].

\subsubsection{Hyperspectral Optical Images}

HyPlant airborne sensor was developed at Forschungszentrum Jülich (Jülich, Germany) in cooperation with Specim Spectral Imaging Ltd. (Oulu, Finland, www.specim.fi). HyPlant was designed as an airborne demonstrator of ESA's Fluorescence Explorer (FLEX) satellite mission. The push-broom imager consists of two modules. First, the dual-channel module is measuring reflected surface radiance in the wavelength range of $0.38-0.97 \mu \mathrm{m}$ with a spectral resolution of $4 \mathrm{~nm}$ (FWHM) at a sampling interval of $1.7 \mathrm{~nm}$ and from $0.97-2.5 \mu \mathrm{m}$ with $13.3 \mathrm{~nm}$ FWHM at $5.5 \mathrm{~nm}$ sampling interval, respectively. Second, the fluorescence module was especially designed to retrieve the emitted fluorescence signal within the atmospheric oxygen bands, $\mathrm{O}_{2}-\mathrm{A}\left(760 \mathrm{~nm}, \mathrm{~F}_{760}\right)$ and $\mathrm{O}_{2}-\mathrm{B}(687 \mathrm{~nm}$, $\mathrm{F}_{687}$ ). Therefore, the fluorescence module provides a very high spectral resolution of $0.25 \mathrm{~nm}$ (FWHM) covering the spectral range from $670-780 \mathrm{~nm}$ resulting in 1024 spectral bands. Therefore, HyPlant is the only available airborne imaging spectrometer offering the detection of the two broadband chlorophyll fluorescence emission peaks at 687 and $760 \mathrm{~nm}$. Further technical details, sensor calibration and image processing are documented in Rascher et al. [33].

The emitted sun-induced chlorophyll fluorescence $\mathrm{F}_{760}$ and $\mathrm{F}_{687}$ were retrieved from HyPlant's fluorescence module images using a Frauenhofer Line Depth (FLD) approach. In detail, the fluorescence 
retrieval implemented for HyPlant is based on the 3FLD approach as initially introduced by Maier et al. [47] and the iFLD method as proposed by Alonso et al. [48]. The method was fundamentally refined and adapted to high performance spectrometers and for airborne fluorescence retrieval. In essence it is complemented with the simulation of atmospheric components using MODTRAN5 [49] in combination with the MODTRAN5 interrogation technique as introduced by Verhoef and Bach [50], and using an empirical constraint based on non-fluorescing reference surfaces (see Wieneke et al. [51] for a recent detailed description of the retrieval method).

Additionally, several reflectance-based narrowband VIs (Table 1) related to plant physiology, structure and water content were calculated from the HyPlant dual-channel module to determine their ability to detect plant water stress symptoms induced by chemical treatments. PRI [24] was calculated using the average of three spectral bands in HyPlant closest to $531 \mathrm{~nm}$ and $570 \mathrm{~nm}$, respectively (centre wavelength \pm 1 band). As simple ratio indices related to water content we applied the Water Index (WI) [52], the Leaf Water Index (LWI) [53] and the Moisture Stress Index (MSI) [22], which are sensitive in the domain of the water absorption bands at $970 \mathrm{~nm}, 1450 \mathrm{~nm}$ and $1600 \mathrm{~nm}$ respectively. Additionally, the Simple Ratio (SR) [54] index and the Normalised Difference Vegetation Index (NDVI) were evaluated [23]. All water content and greenness related indices were calculated with a spectral window of centre wavelength \pm 4 HyPlant spectral bands.

Table 1. Optical visible, near- and shortwave infrared (VNIR/SWIR) narrowband indices grouped by category: (1) xanthophyll pigments, (2) greenness and (3) water content. $R$ is the reflectance centre wavelength of HyPlant Dual Chanel in units of nm.

\begin{tabular}{cccc}
\hline Category & Index & Equation & Reference \\
\hline Xanthophyll & PRI & $P R I=\left(R_{570}-R_{531}\right) /\left(R_{570}+R_{531}\right)$ & Gamon et al. [24] \\
Greenness & SR & $S R=R_{800} / R_{670}$ & Jordan [54] \\
& NDVI & $N D V I=\left(R_{800}-R_{670}\right) /\left(R_{800}+R_{670}\right)$ & Rouse et al. [23] \\
Water content & WI & $W I=R_{900} / R_{970}$ & Peñuelas et al. [52] \\
& LWI & $L W I=R_{1300} / R_{1450}$ & Seelig et al. [53] \\
& MSI & $M S I=R_{1600} / R_{820}$ & Hunt and Rock [22] \\
\hline
\end{tabular}

\subsection{Meteorological Data}

A weather station was set up close to the experimental plots within a non-treated grass area. The station was equipped with a four-band net radiometer (NR01-L Campbell Sci., Logan, UT, USA), an air temperature and humidity sensor (HMP45AC, Vaisala, Helsinki, Finland), measurement of soil water content using Time-domain Reflectrometry (TDR CS616, Campbell Sci., USA), and a canopy temperature sensor (Calex Electronics, Leighton Buzzard, UK). All of the sensors were connected to a data logger (CR1000, Campbell Sci., USA) and acquired at $0.1 \mathrm{~Hz}$, then averaged half hourly. As vapour pressure deficit (VPD) is a more sensitive indicator of water vapour condition than relative humidity $(\mathrm{RH})$ and therefore describes the interaction of plants with the intervening atmosphere more precisely, VPD (hPa) was calculated using Equation (2) [55]:

$$
\begin{gathered}
V P D=e_{S} \times \frac{100-R H}{100} \\
e_{S}=6.11 \times \exp \left(\frac{L}{R v}\left(\frac{1}{273}-\frac{1}{T}\right)\right)
\end{gathered}
$$

where $e_{s}$ is the saturation vapour pressure in mbar, $L$ is the latent heat of vaporization $\left(2.5 \times 10^{6} \mathrm{~J} \mathrm{~kg}^{-1}\right)$, $R v$ is the specific gas constant for water vapour $\left(461 \mathrm{~J} \mathrm{~K}^{-1} \mathrm{~kg}^{-1}\right)$ and $T$ is the current air temperature (K). $\mathrm{RH}$ is the relative humidity (\%).

\subsection{Chamber Flux Measurements}

$\mathrm{CO}_{2}$ and $\mathrm{H}_{2} \mathrm{O}$ flux measurements were taken on 11th June 2014 over plots treated with VG and CR. For logistical reasons no chamber flux measurements were taken at KA treated plots. 
Non-steady-state flow-through a chamber system consisting of transparent and non-transparent chambers was used to measure net ecosystem exchange (NEE) and ecosystem respiration (Reco) fluxes, respectively. Both chambers had a volume of $0.3 \mathrm{~m}^{3}$ and their dimensions were $0.78 \times 0.78 \times 0.50 \mathrm{~m}$. Chambers were equipped with fans, temperature sensor and a vent to equilibrate pressure changes during measurements [56]. Water vapour fluxes were calculated based on measurements taken with transparent chamber made from $3 \mathrm{~mm}$ thick PLEXIGLAS (Clear 0A000 GT, Evonik Industries, Weiterstadt, Germany) [57,58]. Gas concentration changes in the chambers were measured with an infrared gas analyser (LI-840, LICOR, Lincoln, NE, USA) installed in the portable control box equipped with a pump and CR1000 data logger (Campbell Sci., Logan, UT, USA). Air was circulated between the chamber and the analyser in a closed loop with the flow rate of $0.7 \mathrm{~L} \mathrm{~min}^{-1}$. During measurements chambers were fixed to the preinstalled soil frames (one per experimental plot) inserted to soil to $5 \mathrm{~cm}$ depth on 5 th of June 2014. The chamber closure time used for NEE and $\mathrm{H}_{2} \mathrm{O}$ fluxes estimation did not exceed $1 \mathrm{~min}$ to avoid overheating of the chamber headspace and $2 \mathrm{~min}$ for the non-transparent chamber. The chambers were un-cooled in order not to reduce $\mathrm{H}_{2} \mathrm{O}$ fluxes due to condensation on cooling items in accordance with Chojnicki et al. [57] and Acosta et al. [58]. The chamber measurements started at 9:30 in the morning and were continued until 17:00 (CEST), but only measurements taken until the 3rd overpass at 13:40 were considered in analyses corresponding to the Hyper-Cam LW overpasses. There were 10 flux measurements taken on VG and CR plots within this time window.

$\mathrm{H}_{2} \mathrm{O}$ and $\mathrm{CO}_{2}$ fluxes were calculated based on a gas concertation changes over the closure time using the linear regression type as described in Juszczak et al. [56]. In order to avoid underestimation of the fluxes due to a gas saturation, fluxes were calculated from the first 30-40 s of measurements for data with the highest regression slopes in accordance with Hoffmann et al. [59]. Coefficient of determination $\left(\mathrm{R}^{2}\right)$ for the fluxes considered in analyses exceeds 0.9 .

Gross Ecosystem Productivity (GEP), indicating the amount of $\mathrm{CO}_{2}$ assimilated by grass in photosynthesis, was calculated as a sum of absolute NEE and Reco values from the two consecutive measurements of NEE and Reco (Reco was measured just after NEE).

Incoming PAR was measured continuously by a PAR quantum sensor (SKP215, Skye Instruments, Llandrindod Wells, UK) installed on a weather station located approximately $100 \mathrm{~m}$ from the experimental plots. Considering that chamber flux measurements were taken at CR and VG plots at different times and under different PAR and temperature conditions, the $\mathrm{H}_{2} \mathrm{O}$ fluxes were normalised over PAR, dividing $\mathrm{H}_{2} \mathrm{O}$ fluxes by PAR (both in $\mu$ mols $\mathrm{m}^{-2} \mathrm{~s}^{-1}$ ).

\subsection{Statistical Analysis}

For statistical analysis, we used R [60] and the R package nlme [61] to perform a linear mixed effects model to describe the nested structure of our experimental setup. An interaction term between the variables treatment and flight time was introduced as fixed effects, because we were rather interested in the comparison of the treatments at each flight time and less in the differences between the treatments accumulated over all three overpasses. As random effects, we set the variable ID (flight: treatment: plot), which describes the nesting of the variables plot within treatment and treatment within flight as well as the repeated measure problem of the three overpasses. To take care of the autocorrelation of neighbouring pixels within each plot, we included a Gaussian spatial correlation structure term in the model for the residuals, which considered a distance $(\mathrm{d})$ dependent correlation following a Gaussian distribution for a certain range $(\mathrm{r})\left(\exp \left\{-\left[\left(\mathrm{r}_{1-2}\right) / \mathrm{d}\right]^{2}\right\}\right)$. The overall number of observation is $n=864$, 3 treatments with 3 repetitions each by 3 flights by 32 pixels per plot. Visual inspection of residual plots did not reveal any obvious deviations from homoscedasticity or normality. For pairwise comparison we used a student $t$-statistic with a 0.05 Tukey-adjusted significance level, which is implemented in the $\mathrm{R}$ package lsmeans [62]. 


\section{Results}

\subsection{Meteorological Data}

Figure 2 shows the diurnal variations of environmental conditions (net radiation (Rn), air temperature $\left(T_{\text {air }}\right)$, surface temperature $\left(T_{s}\right)$, the difference of $T_{S}$ and $T_{\text {air }}$, and vapour pressure deficit (VPD) as well as soil water content (SWC)) for 11th and 12th of June from sunrise (05:30 CEST) until sunset (21:00 CEST). The meteorological data were retrieved from the weather station measurements (see Section 2.2). Measurements were taken over an untreated site and can therefore be considered as a Control (CR) plot. In fact, no major differences were observed between the 11th and 12th of June. For both dates, Rn steeply increased from $0 \mathrm{Wm}^{-2}$ to a maximum of $670 \mathrm{Wm}^{-2}$ around solar noon, before it decreased again. $T_{\text {air }}$ and $T_{S}$ also rapidly rose on the 11th June until solar noon from 19.7-32.6 ${ }^{\circ} \mathrm{C}$ and $14.6-32.4^{\circ} \mathrm{C}$, respectively. Almost similar temperatures were observed on the 12th of June. Similarly, VPD almost increased tenfold (3.8-31.5 hPa) until 13:30 (CEST) for both dates. After solar noon, $T_{S}$ decreased, whereas $T_{\text {air }}$ and VPD still rose until late afternoon. This decrease of $T_{\mathcal{S}}$ with a simultaneously increase of $T_{\text {air }}$ and the high capability of potential transpiration characterised by high VPD values, results from evaporative cooling and indicates plants are highly transpiring in the afternoon. Thus, we can state that during the 11th and 12th of June 2014 plant water supply over control plots was sufficient and no actual water stress prevailed, which is in very good agreement with the constant values of SWC (Figure 2).

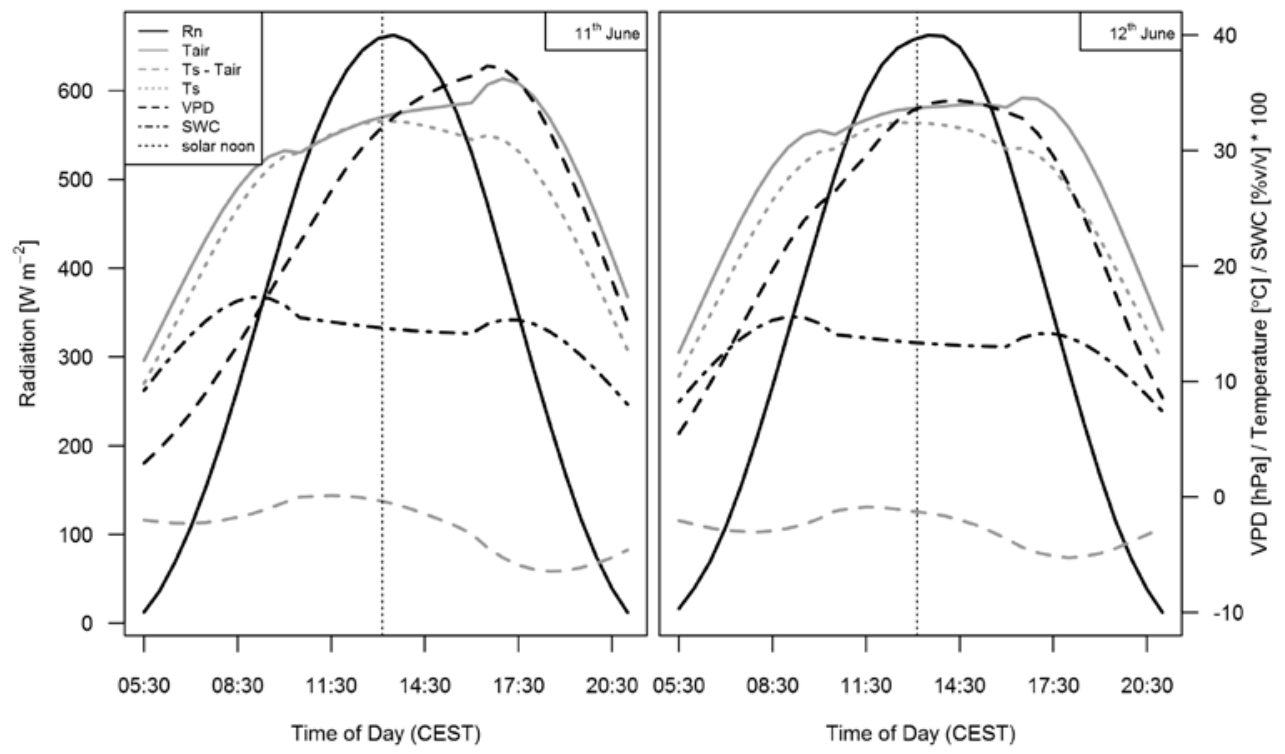

Figure 2. Environmental conditions (net radiation $(\mathrm{Rn})$, air temperature $\left(T_{\text {air }}\right)$, surface temperature $\left(T_{s}\right)$, $T_{S}-T_{\text {air }}$, vapour pressure deficit (VPD), as well as soil water content (SWC)) for 11th and 12th of June 2014 over a non-treated grass surface measured by the weather station.

\subsection{Chamber Flux Measurements}

Figure 3 shows the diurnal course of $\mathrm{H}_{2} \mathrm{O}$ flux (solid lines) and PAR (dashed lines) for CR (green) and VG (orange) treatments observed by chamber flux measurements. During the day, $\mathrm{H}_{2} \mathrm{O}$ flux and PAR increased until solar noon. The observed variations in the measured fluxes might reflect the differences between plots (measurements were taken on three CR and three VG plots). The average $\mathrm{H}_{2} \mathrm{O}$ flux rates $(n=10$, both for CR and VG) for the time between 09:30 and 13:40 (CEST) was 20\% higher on average for CR plots $\left(10.6 \pm 2.61 \mathrm{mmols}_{2} \mathrm{O} \mathrm{m}^{-2} \mathrm{~s}^{-1}\right)$ than for VG plots $(8.44 \pm 3.21 \mathrm{mmols}$ $\left.\mathrm{H}_{2} \mathrm{O} \mathrm{m}^{-2} \mathrm{~s}^{-1}\right)$, although this difference was not significant ( $p=0.11$, Figure 3 lower left). Considering that measurements were taken at different time and under different PAR and temperature conditions, 
the $\mathrm{H}_{2} \mathrm{O}$ fluxes were normalised over PAR (Figure 3 lower right). After normalisation with PAR the difference between VG and CR transpiration was significant $\left(p<0.05^{*}\right)$, which proves that VG substantially reduced transpiration.
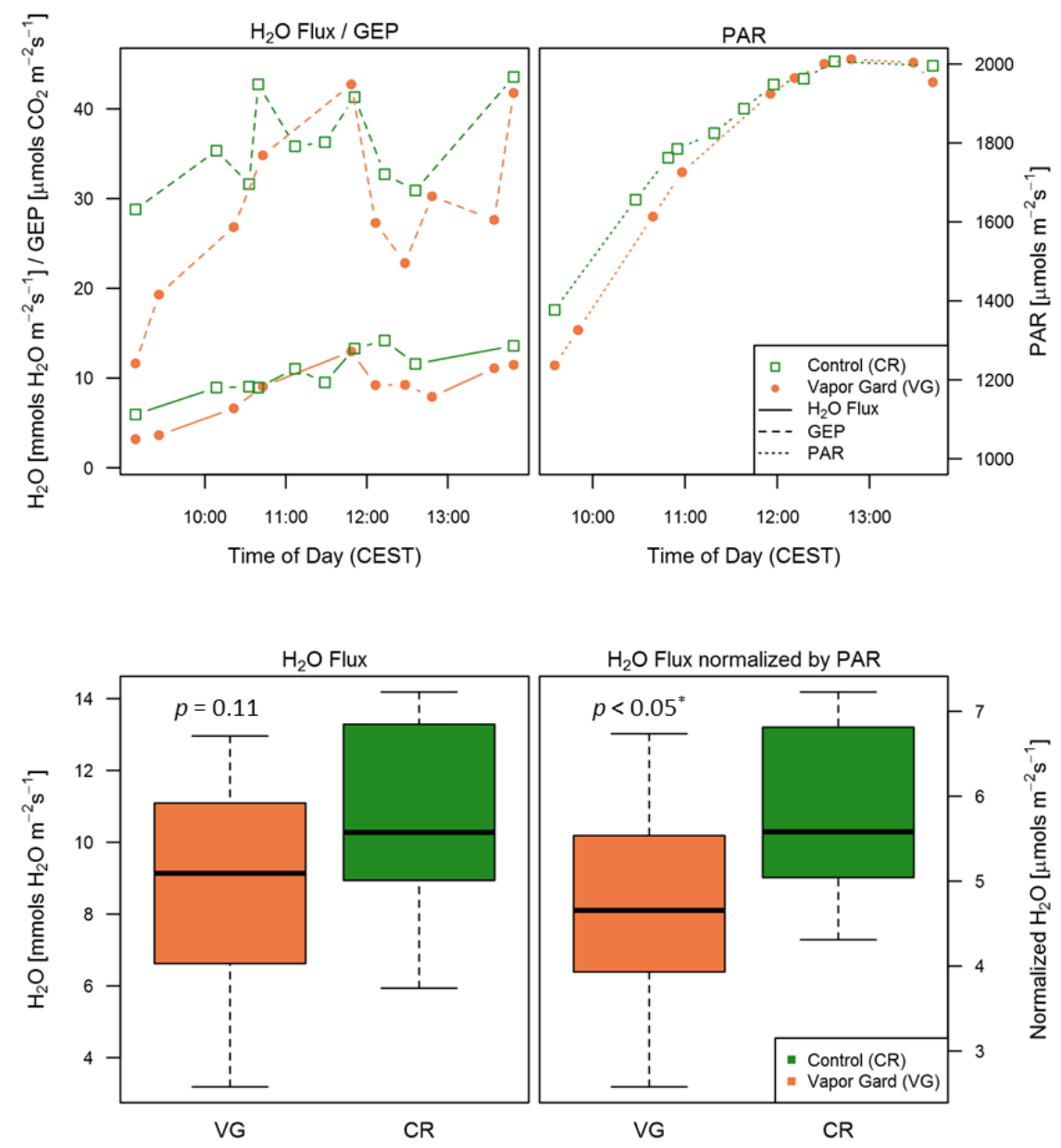

Figure 3. Diurnal changes in chamber flux measurements for Control plot (CR) (green) and Vapor Gard $^{\circledR}$ (VG) (orange) treatments. Solid lines are showing $\mathrm{H}_{2} \mathrm{O}$ fluxes in mmols $\mathrm{H}_{2} \mathrm{O} \mathrm{m}^{-2} \mathrm{~s}^{-1}$ and Gross Ecosystem Productivity (GEP) is represented in dashed lines measured in $\mu$ mols $\mathrm{CO}_{2} \mathrm{~m}^{-2} \mathrm{~s}^{-1}$ (upper left). PAR (Photosynthetically Active Radiation) as measured in $\mu$ mols $\mathrm{m}^{-2} \mathrm{~s}^{-1}$ is represented with dotted lines (upper right). Boxplots for $\mathrm{H}_{2} \mathrm{O}$ fluxes (lower left) and $\mathrm{H}_{2} \mathrm{O}$ fluxes normalised by PAR (lower right).

The average GEP ( $n=10$, both for CR and VG) for the same time between 09:30 and 13:40 (CEST) was $21 \%$ higher $(p<0.01 * *)$ for CR plots $\left(35.91 \pm 5.15 \mu\right.$ mols $\left.\mathrm{CO}_{2} \mathrm{~m}^{-2} \mathrm{~s}^{-1}\right)$ than for VG plots $\left(28.51 \pm 9.59 \mu \mathrm{mols} \mathrm{CO}_{2} \mathrm{~m}^{2} \mathrm{~s}^{-1}\right)$.

\subsection{Thermal Images}

\subsubsection{Accuracy of Temperature Images}

Image temperatures retrieved from the TIR airborne sensor (Telops Hyper-Cam LW) were compared with ground temperatures of the water filled pool at each overpass (Table 2). Overall, the airborne image temperatures agree very well with the ground temperatures with less than $0.35 \mathrm{~K}$ averaged absolute error, which is within the accuracy of the thermocouples $(0.5 \mathrm{~K}$, see above). The observed error increased with increasing temperature (i.e., $\Delta T=0.19$ at $09: 18$ and $\Delta T=0.49$ at $12: 51$ ). In comparison, 
using a single band of the airborne hyperspectral scanner (AHS), Sobrino et al. [63] were only able to retrieve surface temperatures with an accuracy of $2 \mathrm{~K}$.

Table 2. Ground ( $\left.T_{\text {ground }}\right)$ and airborne $\left(T_{\text {airborne }}\right)$ temperatures of a water filled pool and their differences $(\Delta T)$ per TIR airborne overpass.

\begin{tabular}{ccccc}
\hline Date & Flight & $\boldsymbol{T}_{\text {ground }}$ & $\boldsymbol{T}_{\text {airborne }}$ & $\boldsymbol{\Delta} \boldsymbol{T}$ \\
\hline 11/06/2014 09:18 & 1 & 297.69 & 297.5 & 0.19 \\
11/06/2014 10:48 & 2 & 299.41 & 299.79 & 0.38 \\
11/06/2014 12:51 & 3 & 301.21 & 301.7 & 0.49 \\
\hline
\end{tabular}

\subsubsection{Temperature-Based Indices}

Maps of temperature-based indices (Figure 4) as well as boxplots (Figure 5) show diurnal changes within the experimental site and treatments. It can be noted that the relative relationships (order) among the three treatments were consistent for all indicators and all flights (Figure 5, Appendix A, Table A1 for mean $(\bar{x})$ and standard deviation $(s d)$ of each index per flight and treatment).

For the CR plots, $T_{S}$ was lowest in the early morning (09:18) with $301.43 \pm 0.21 \mathrm{~K}$ and increased by more than $6 \mathrm{~K}$ to $307.53 \pm 0.44 \mathrm{~K}$ in the late morning (10:48). From late morning to midday (12:51), $T_{s}$ remained almost constant $(307.99 \pm 0.14 \mathrm{~K}) . T_{s}-T_{\text {air }}$ was also lowest in the early morning $(0.97 \pm 0.21 \mathrm{~K})$, increased to late morning $(3.5 \pm 0.44 \mathrm{~K})$ and then slightly decreased by midday $(2.3 \pm 0.14 \mathrm{~K})$. Finally, CWSI values also increased from early $(0.08 \pm 0.04)$ to late morning $(0.44 \pm 0.2)$, but decreased almost towards initial values during midday $(0.11 \pm 0.04)$. Diurnal courses of VG and KA treatment plots were similar to those of CR plots.

A distinct pattern between all temperature-based indices was recognized (Figure 5), with KA was showing the lowest values in comparison to $C R$, whereas VG had the highest for all three flights (e.g., $T_{S}(\mathrm{KA})=301.03 \mathrm{~K}, \mathrm{~T}_{\mathrm{S}}(\mathrm{CR})=301.43 \mathrm{~K}$ and $\mathrm{T}_{\mathrm{S}}(\mathrm{VG})=302.42 \mathrm{~K}$ at early morning). A pairwise comparison of the treatments (see Tukey's HSD (Honestly Significant Difference) in Appendix A, Table A2) revealed that in the early morning VG and CR were significantly different for $T_{s}$ and $T_{S}-T_{\text {air }}$, but not for CWSI $(p=0.59)$. However, VG plots could be easily distinguished from CR and surroundings by visual interpretation of the CWSI map at early morning (Figure 4). Additionally, the boxplots of CWSI also showed a distinct difference between CR and VG treatment at early morning. Thus, all temperature-based indices showed considerably increased values for the VG treatment at early morning. By contrast, for the late morning and midday flights VG had no significant effect $(p>0.05)$ to any temperature-based index. Similar results were observed for KA, where for all temperature-based indices only at late morning KA was significantly different to CR. 

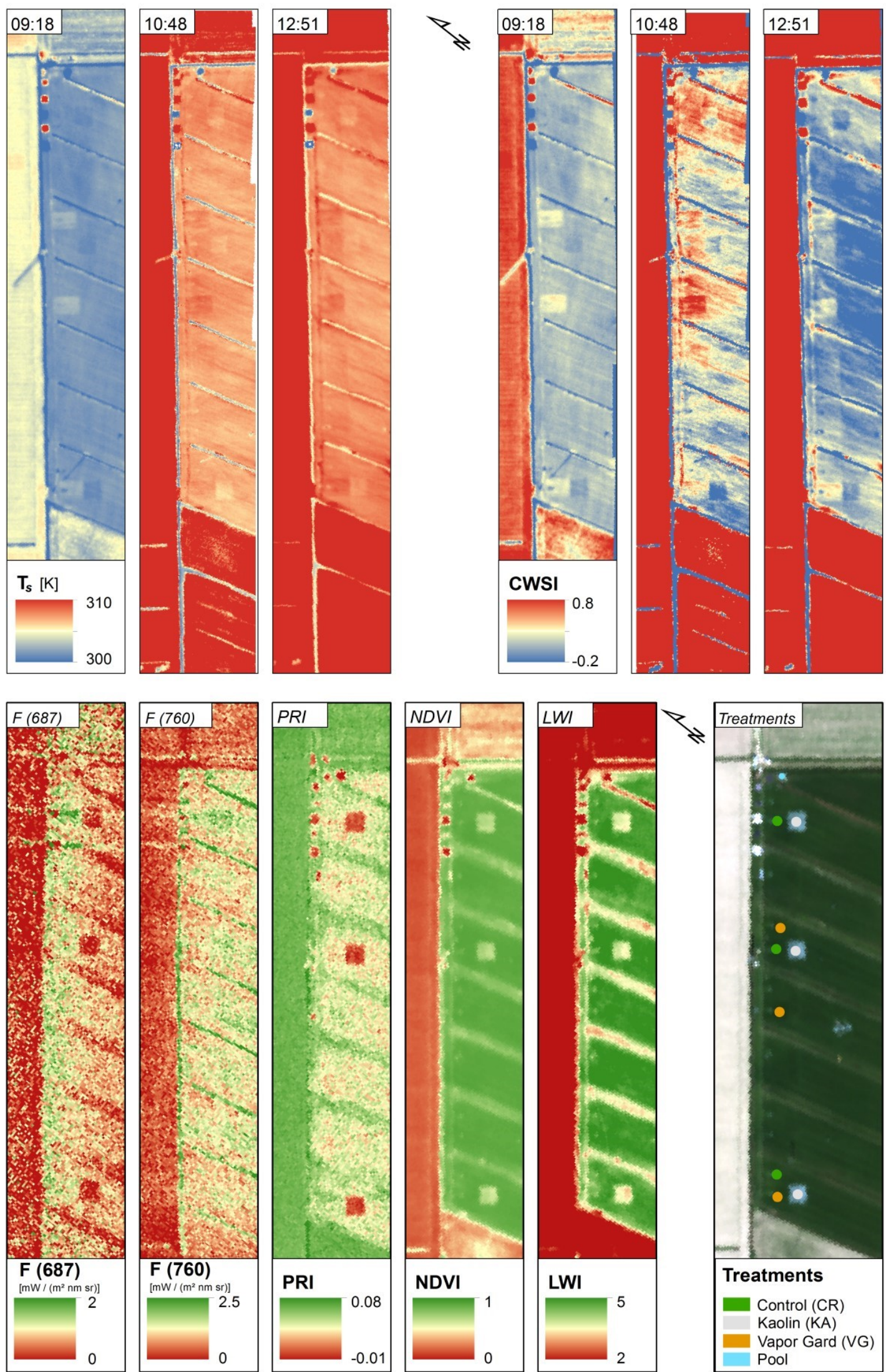

$25 \quad 50 \quad 100$ Meters

Figure 4. Diurnal $T_{S}[K]$ and CWSI maps at 11th June (top), $F_{687}, F_{760}$, PRI, NDVI and LWI maps of the same day (11th June, 14:52 CEST) (bottom left), and locations of the treatments (bottom right). 

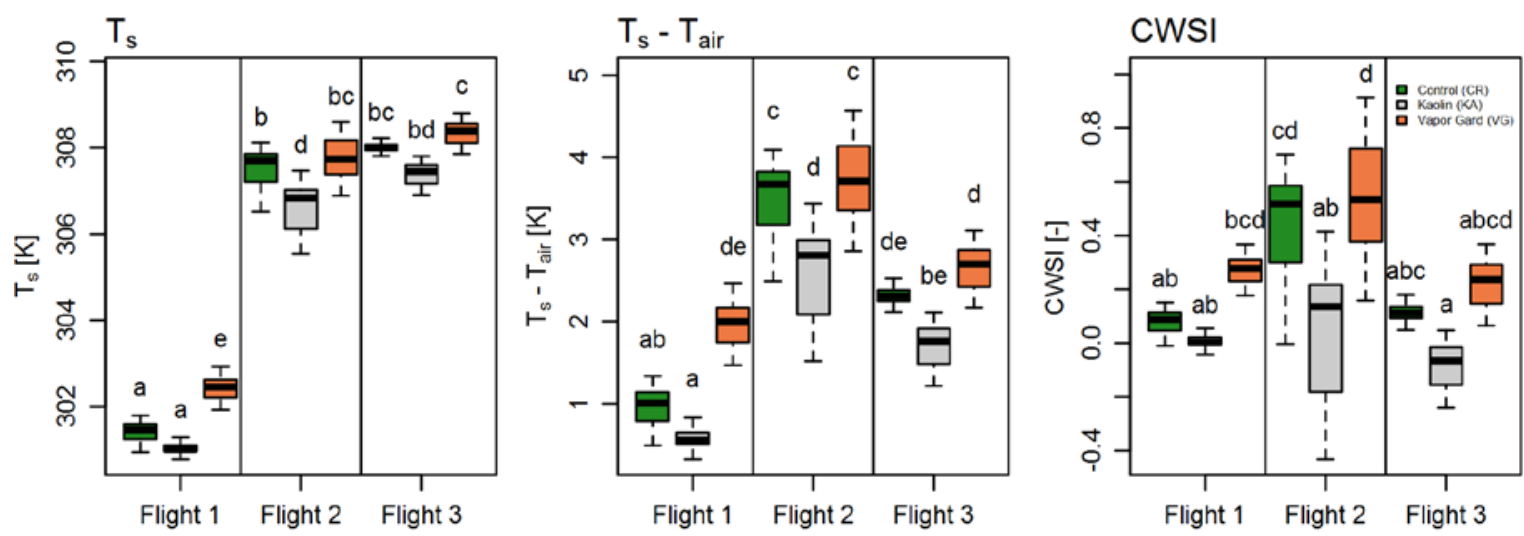

Figure 5. Boxplots of the different treatments (CR, KA, VG) at the three overpasses for $T_{s}, T_{S}-T_{\text {air }}$ and CWSI. Different letters indicate significant differences $\left({ }^{*} p \leq 0.05\right)$.

\subsection{VNIR/SWIR Indices and Sun-Induced Fluorescence (SIF)}

Figure 6 shows the mean reflectance spectra from HyPlant's dual-channel module $(0.38-2.5 \mu \mathrm{m})$ per treatment and flight. The reflectance spectra for VG plots were very similar to $C R$, which is also confirmed by the boxplots (Figure 7) as well as by the $p$-values (see Appendix A, Table A3). Furthermore, no visual differences between VG and CR were recognized in the HyPlant images from the maps (Figure 4). In contrast, KA mean reflectance spectra had an overall higher reflectance for all wavelengths. In particular, in the visible spectral range $(0.38-0.7 \mu \mathrm{m}) \mathrm{KA}$ displayed up to $10 \%$ higher (about 5 times larger) reflectance values, underpinning the properties of KA to increase plant albedo.
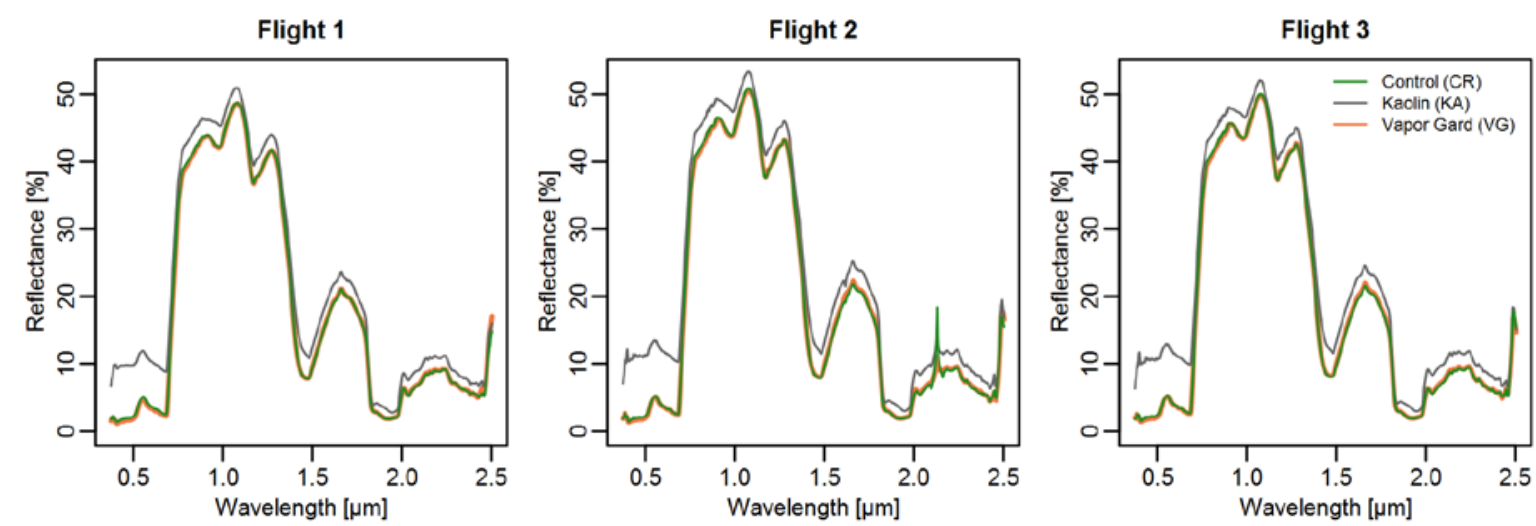

Figure 6. VNIR/SWIR mean reflectance spectra from HyPlant's dual-channel module.

To test for any structural changes that may have occurred because of plant growth or stress (e.g., leaf rolling, leaf angle) in the course of the campaign, we evaluated the structural indices NDVI and SR that were derived from VNIR/SWIR spectra over the three acquisitions. Both structural indices were not significantly different at the three airborne overpasses (Figure 7), as shown by a pairwise Tukey's HSD post-hoc test (see Appendix A, Table A3). The similarity of all three NDVI and SR values suggests stable data collection (good repeatability). Again, NDVI and SR behaved in a similar manner over both chemical agents (Figure 7). They reacted highly significant to the fact that the KA increased overall reflectance (see above) in comparison to CR plots $\left(p<0.001^{* * *}\right.$, see Appendix A Table A3). In contrast, VG had no significant effect on the grass surface reflectance in comparison to CR (VG and CR are almost identical, Figure 6). Further, VG had no significant effect on NDVI and SR as reported by very small mean differences between VG and CR (e.g., 0.01 at early morning and even 0 for late morning and midday for NDVI, see Appendix A, Table A1). 

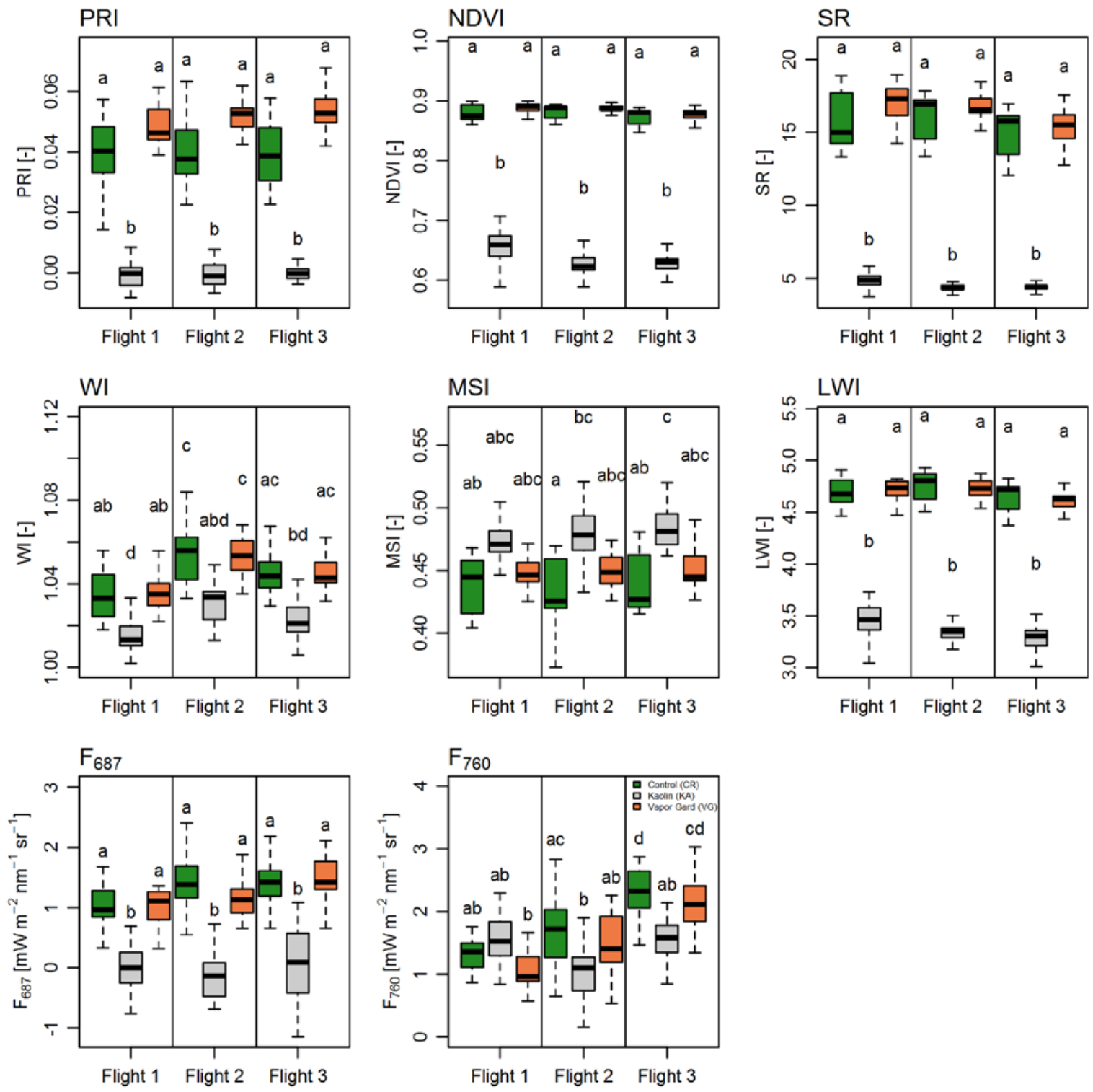

Figure 7. Boxplots of the different treatments (CR, KA, and VG) at three HyPlant overpasses for VNIR/SWIR based indices and $\mathrm{F}_{687}$ and $\mathrm{F}_{760}$. Different letters indicate significant differences $\left({ }^{*} p \leq 0.05\right)$.

The performance of reflectance-based VIs to detect plant (water) stress was tested using PRI, as well as water content related indices (i.e., WI, LWI, MSI). As KA greatly changed the reflectance in the green spectral range (Figure 6), the PRI was also greatly affected in comparison to CR. No significant differences between VG and CR plots could be recognized for PRI. However, PRI values are slightly increased in the VG treatment (Figure 7). Furthermore, the water absorption bands at 0.97 and $1.45 \mu \mathrm{m}$, which were used in the WI and LWI, respectively, were also highly sensitive to the KA treatment compared to CR. In fact, the KA plots could be easily distinguished from the surrounding areas looking at PRI, NDVI and LWI maps (Figure 4). Just MSI was less sensitive and only indicated significantly differences for late morning and midday.

As a fundamental difference to reflectance-based VI, SIF is an emitted radiation. Therefore, SIF is not directly affected by changing the reflectance properties of grass surface by chemical agent, but rather indirectly by induced plant photochemical changes. $\mathrm{F}_{687}$ shows slightly negative values for KA. However, the overall pattern of $\mathrm{F}_{687}$ and $\mathrm{F}_{760}$ displays consistently lower values in KA plots (Figure 7), except for $\mathrm{F}_{760}$ at the first HyPlant overpass. The differences between KA and CR 
were up to $1.6 \mathrm{~mW} \mathrm{~nm} \mathrm{mr}^{-1} \mathrm{sr}^{-1} \mathrm{~m}^{-2}$ for $\mathrm{F}_{687}$ and $0.7 \mathrm{~mW} \mathrm{~nm}^{-1} \mathrm{sr}^{-1} \mathrm{~m}^{-2}$ for $\mathrm{F}_{760}$ during the second HyPlant overpass. Thus, $\mathrm{F}_{687}$ and $\mathrm{F}_{760}$ of KA plots are significantly different in comparison to $\mathrm{CR}$ (see Appendix A Table A3). In contrast, VG has no effect on $\mathrm{F}_{687}$ and $\mathrm{F}_{760}$ compared to CR.

\section{Discussion}

As shown by the results of the meteorological measurements (i.e., SWC, VPD; Figure 2) no actual plant water stress occurred during the experiment due to sufficient water supply from the soil. Nevertheless, the VG treatment had a modest but clearly measurable effect on $\mathrm{H}_{2} \mathrm{O}$ flux relative to PAR (reduction of relative transpiration of grass by $20 \%$ on average) as well as on $\mathrm{CO}_{2}$ flux (reduction by nearly $21 \%$ ). This proved that real, but rather mild effects on transpiration and $\mathrm{CO}_{2}$ uptake arose from the VG treatment.

The diurnal change of $T_{s}$ can be explained by the effects of plant transpiration. At late morning, as a consequence of increasing net radiation and VPD (Figure 2), plant transpiration and thus, evaporative cooling increased and prevented a rise in $T_{s}$. Due to the same process, $T_{s}-T_{a i r}$ also increased from early to late morning. However, $T_{s}-T_{\text {air }}$ slightly decreased from late morning to midday (Figure 5) because $T_{s}$ remained constant due to higher transpiration rate while $T_{\text {air }}$ continued to rise due to increased net radiation (Figure 2). Furthermore, the diurnal changes in CWSI demonstrated the same effect as described for $T_{S}-T_{\text {air }}$. Since the upper boundary $\left(T_{d r y}\right)$ was determined by adding $5 \mathrm{~K}$ to the current $T_{a i r}, T_{d r y}$ increased in the same manner as $T_{\text {air }}$ resulting in overall lower CWSI values at midday. Negative CWSI values in KA resulted from the fact that $T_{s}$ was lowest for KA and the lower boundary $\left(T_{\text {weet }}\right)$ was determined by the coolest $5 \%$ of CR plots, which were partly warmer than KA.

Indeed, the mild physiological manipulations through the chemical agents (i.e., $20 \%$ reduced transpiration in VG) only induced very small effects to temperature-based indices. VG reduced plant transpiration and induced symptoms of water stress, i.e., an overall increase in $T_{s}$ compared to CR plots. Contrary, the KA treatment highly increased the plant albedo, and thus reduced the overall energy uptake by the plant causing a decrease in $T_{s}$. In this study, only absolute temperature differences of less than $1.0 \mathrm{~K}$ were observed between the treatments. Nevertheless, these minor differences could be distinguished by TIR remote sensing, as observed by a distinct pattern for all temperature-based indices (Figure 5). These results demonstrate that TIR remote sensing indices were sensitive to small $T_{S}$ differences induced by the chemical treatments. In comparison, a recent study has demonstrated that temperature-based indices can detect water stress from airborne multispectral TIR data under distinct water deficit conditions with large temperature difference of up to $4.7 \mathrm{~K}[13,14]$. However, our results indicate that the TIR-based indices can be used to detect minor or moderate level of water stress. It is well known that the leaf temperature can be increased by various stressors including water deficit and diseases $[64,65]$. Therefore, TIR imaging of high spatial and spectral resolution greatly contributes to the detection and/or quantification of the physiological anomaly caused by abiotic and biotic stresses.

Basically, canopy reflectance spectra in VNIR/SWIR are affected by water content, pigment content and composition (chlorophyll, carotenoid, xanthophyll), leaf internal structure, and canopy geometry e.g., Reference [66]. Thus, in turn, the stress symptoms are detected via the spectral change associated to the response of these physiological traits to environmental stressors. In this study, we assumed little change in water and chlorophyll content as well as in structure among CR, KA and VG treatments. The response of all analysed VIs (PRI, NDVI, WI, LWI, MSI) that are closely related to either structure, water and pigment, or physiological functioning showed little difference between $\mathrm{CR}$ and VG. This fact suggests the consistency of these VIs in various conditions. On the other hand, the significant differences found between CR and KA imply that care should be taken in the application of these VIs to some specific leaf surface conditions (e.g., after yellow-sand dust and volcanic ash fall). In such cases, the surface reflectance spectra could be altered (as in KA treatment) without any physiological changes. Generally, the applicability of normalised VIs is based on the consistent relationship of multiple bands to the internal physiological changes. Accordingly, alteration of the relationship between spectral bands (i.e., shape of spectra) caused by external factors would 
strongly hamper the consistency of VIs. In fact, KA treatment increased plant albedo, but did not increase reflectance at the same ratio in all wavebands. Thus, the significant difference in KA was not caused by physiological changes, but rather indicated abnormal alteration of reflectance spectra. Since reflectance spectra is altered unusually by plant diseases such as powdery mildew and rust diseases e.g., Reference [67], similar unusual changes of VIs as in KA would be detected by hyperspectral measurement. Therefore, our results from the unique experimental design provide useful insights on the consistency and usefulness of hyperspectral reflectance measurements, especially for discrimination of causes of detected changes.

According to previous research [30], SIF decreases with a reduction of photosynthesis under high light and stressed conditions (e.g., shortage in water availability). However, in our experiment, SIF indices showed no significant difference between VG and CR treatments while the photosynthetic efficiency should have been lowered in VG plots because of reduced $\mathrm{H}_{2} \mathrm{O}$ and $\mathrm{CO}_{2}$ fluxes (as proved by chamber flux measurements). This fact suggests that either the stress was too subtle to reduce photosynthesis, and thus had no influence on the efficiency of photosynthetic light reaction or that the used SIF indices were not sufficiently sensitive to detect the slight photosynthesis reduction. On the other hand, the significant reduction in SIF indices $\left(\mathrm{F}_{687}, \mathrm{~F}_{760}\right)$ found under KA treatment is proportionally related to the reduced amount of APAR (Absorbed Photosynthetically Active Radiation) by increasing surface reflectance, and thus lowered the photosynthetic rate. Nevertheless, it is not clear whether the reduction of SIF was directly related to the change of photosynthetic photon use efficiency because the fraction of APAR (fAPAR) as well as water and chlorophyll content remained unchanged. In addition, one has to be careful about appropriate conclusions regarding the attenuation of SIF and incident PAR at leaf surfaces. It is still not obvious how SIF can be related to photochemistry and identifying a unique relationship between SIF and photochemical efficiency is challenging [31]. The slightly negative values in $F_{687}$ originate from uncertainties in the $F_{687}$ retrieval due to the largely modified surface reflectance by the KA treatment. However, our results clearly show that the subtle change in SIF indices for KA treatments was detected by the HyPlant sensor. Therefore, optical hyperspectral techniques bear the ability to detect both rapid photochemical change (e.g., photon use efficiency) and integrated physiological change (e.g., photosynthetic capacity), and to identify the causes for the changes by using multiple wavelengths. Since remotely sensed SIF is affected by the non-linear interactions of photochemical, physiological and biophysical factors, further experimental studies in combination with process-based modelling e.g., Reference [68], are needed for both scientific and industrial applications.

In fact, the interpretation of the results presented here with regard to real water stress occurrence in natural conditions is limited due to: (i) logistical challenges related to synchronous flight plan of both airborne sensor systems HyPlant and HyperCam-LW which complicated the comparison of TIR versus VNIR/SWIR and SIF water stress indices, and (ii) instead of a real water stress occurrence only water stress symptoms were simulated by the chemical agents (i.e., VG and KA). Nevertheless, the study allowed us to deduce new findings about the sensitivity and the interplay of different indices in relation to water stress symptoms as induced by chemical agents at the airborne level.

In general, biotic and abiotic plant stressors (e.g., water stress, heat stress, and diseases) often occur simultaneously and cause similar plant physiological responses (e.g., increase in plant temperature, reduced photosynthetic efficiency, and change in canopy structure). Therefore, multi-sensor and multi-temporal approaches have a great potential to obtain useful information not only about the current plant status but also on the causes of biophysical, physiological and photochemical changes. In particular, airborne remote sensing with its high spatial and temporal resolutions can bridge the gap between in situ and satellite observations.

\section{Conclusions}

In this paper, we examined the performance of different airborne hyperspectral remote sensing approaches (i.e., TIR, VNIR/SWIR and SIF) for detecting the subtle effects caused by chemical agents 
over a commercial grass farm. The two chemical agents (i.e., VG and KA) induced symptoms similar to those that can be expected from the occurrence of water stress. From the VG treatment, real but rather mild effects on plant transpiration and $\mathrm{CO}_{2}$ uptake arose. From the KA treatment, plant albedo was increased.

Although a direct comparison of the spectral domains regarding their performance of real water stress detection is not reliable, the most important finding of this study is that the TIR domain was highly sensible to subtle changes in the temperature regime as induced by VG and KA, whereas VNIR/SWIR and SIF domains were less affected by the artificial water stress symptoms. Furthermore, the assessment of the observed effects of the treatments on the different indices is summarised in Table 3. First, $T_{s}$ was increased in VG plots due to decreased plant transpiration. Similarly, also the diurnal changes in temperature-based indices were caused by plant transpiration. Second, SIF indices were not affected in VG plots because the changes in photosynthetic efficiency were too subtle. Third, VNIR/SWIR indices were also not affected in VG plots due to unchanged leaf biochemical components. Fourth, KA treatment increased plant albedo, reduced APAR resulting in a reduction of $T_{s}$, in a reduction of SIF, and in a change of VNIR/SWIR indices (see Table 3 for details). Finally, a multi-sensor approach not only provides useful information about the current plant status but also on the causes of biophysical, physiological and photochemical changes.

Table 3. Observed effects of treatments on spectral domains.

\begin{tabular}{clcl}
\hline Treatment & \multicolumn{1}{c}{ Effect on VNIR/SWIR } & \multicolumn{1}{c}{ Effect on TIR } & \multicolumn{1}{c}{ Effect on SIF } \\
\hline CR & \multicolumn{1}{c}{ Normal } & \multicolumn{1}{c}{ Normal } & Normal \\
\hline VG & $\begin{array}{l}\text { Indices sensitive to leaf water } \\
\text { content and chlorophyll content } \\
\text { remained unchanged. }\end{array}$ & $\begin{array}{l}T_{S} \text { was increased due to } \\
\text { reduced transpiration. }\end{array}$ & $\begin{array}{l}\text { SIF indices remained } \\
\text { unchanged probably due to } \\
\text { too subtle changes in } \\
\text { photosynthetic efficiency. }\end{array}$ \\
\hline KA & $\begin{array}{l}\text { Indices were highly sensitive to an } \\
\text { overall increase in reflectance and } \\
\text { corresponding reduction of APAR } \\
\text { (Absorbed Photosynthetically } \\
\text { Active Radiation). }\end{array}$ & $\begin{array}{l}T_{S} \text { was reduced due to a } \\
\text { decrease in absorbed } \\
\text { radiation. }\end{array}$ & $\begin{array}{l}\text { SIF indices were reduced due } \\
\text { to decreased overall available } \\
\text { absorbed energy (APAR). }\end{array}$ \\
\hline
\end{tabular}

Author Contributions: Writing—original draft: M.G.; writing—review and editing: all authors; conceptualization: F.M., G.A., M.S., and M.G.; methodology: M.G., T.U., U.R., and R.J.; data curation: M.G., U.R., G.A., and R.J.; formal analysis: M.G.; supervision: T.U., M.S., and Y.I; funding acquisition: M.S., T.U., and U.R.

Funding: Funding for this research was provided by the Fonds National de la Recherche (FNR) of Luxembourg, particularly through the PLANTSENS project grant (Detection of plant stress using advanced thermal and spectral remote sensing techniques for improved crop management, C13/SR/5894876) and the FNR-DFG CAOS-2 project grant (Catchments as Organised Systems, INTER/DFG/14/02). The development of HyPlant was supported by the large-scale investment grant of the Forschungszentrum Jülich. Campaign activities were funded by the European Space Agency (ESA) in the frame of the FLEX-EU activity (ESA Contract No. 4000107143/12/NL/FF/If). Further support was provided by the SFB/TR32 "Patterns in Soil-Vegetation-Atmosphere Systems: Monitoring, Modelling, and Data Assimilation"—subproject D2 (www. tr32.de), funded by the Deutsche Forschungsgemeinschaft (DFG) and the German Plant Phenotyping Network (DPPN), funded by the BMBF.

Acknowledgments: This study was also supported in part by JSPS and CSTI-SIP, Japan. Furthermore, we would like to thank everyone who took part in the campaign, in particular for the airborne operation of the Hyper-Cam-LW (Franz Kai Ronellenfitsch, LIST), for ground measurements and data processing (Gilles Rock, Karolina Sakowska, Marcin Stróżecki, Micol Rossini, Marco Celesti, Anke Schickling, Patrick Rademske, Alexander Damm, Francisco Pinto, Andreas Burkart and all the others) and for the campaign coordination (Dirk Schüttemeyer, ESA). I would like to particularly thank Yoshio Inoue for his scientific input and his generous support.

Conflicts of Interest: The authors declare no conflicts of interest. 


\section{Appendix A}

Table A1. Descriptive statistics: mean $(\bar{x})$ and standard deviation $(s d)$ for every index per flight and treatment (Control (CR), Kaolin (KA) and Vapor Gard $\left.{ }^{\circledR}(\mathrm{VG})\right)$.

\begin{tabular}{|c|c|c|c|c|c|c|c|c|c|c|c|c|c|}
\hline Flight & Treat & $\bar{x} / s d$ & $T_{s}$ & $T_{s}-T_{a i r}$ & CWSI & PRI & NDVI & SR & WI & MSI & LWI & $F_{687}$ & $F_{760}$ \\
\hline \multirow{6}{*}{1} & \multirow{2}{*}{$\mathrm{CR}$} & $\bar{x}$ & 301.43 & 0.97 & 0.08 & 0.04 & 0.88 & 15.7 & 1.04 & 0.44 & 4.7 & 1.08 & 1.29 \\
\hline & & sd & 0.21 & 0.21 & 0.04 & 0.01 & 0.01 & 1.75 & 0.01 & 0.02 & 0.12 & 0.40 & 0.25 \\
\hline & \multirow{2}{*}{ KA } & $\bar{x}$ & 301.03 & 0.57 & 0.01 & 0 & 0.65 & 4.82 & 1.01 & 0.47 & 3.43 & 0.03 & 1.52 \\
\hline & & sd & 0.1 & 0.1 & 0.02 & 0 & 0.03 & 0.46 & 0.01 & 0.02 & 0.18 & 0.40 & 0.39 \\
\hline & \multirow{2}{*}{ VG } & $\bar{x}$ & 302.42 & 1.96 & 0.27 & 0.05 & 0.89 & 17.1 & 1.04 & 0.45 & 4.71 & 1.02 & 1.07 \\
\hline & & sd & 0.23 & 0.23 & 0.04 & 0.01 & 0.01 & 1.1 & 0.01 & 0.01 & 0.09 & 0.29 & 0.26 \\
\hline \multirow{6}{*}{2} & \multirow{2}{*}{$\mathrm{CR}$} & $\bar{x}$ & 307.53 & 3.5 & 0.44 & 0.04 & 0.88 & 16.14 & 1.05 & 0.43 & 4.76 & 1.48 & 1.66 \\
\hline & & sd & 0.44 & 0.44 & 0.20 & 0.01 & 0.01 & 1.39 & 0.01 & 0.03 & 0.13 & 0.55 & 0.48 \\
\hline & \multirow{2}{*}{$\mathrm{KA}$} & $\bar{x}$ & 306.65 & 2.62 & 0.05 & 0 & 0.62 & 4.33 & 1.03 & 0.47 & 3.33 & -0.13 & 1.02 \\
\hline & & sd & 0.51 & 0.51 & 0.22 & 0 & 0.02 & 0.28 & 0.01 & 0.02 & 0.12 & 0.36 & 0.46 \\
\hline & \multirow{2}{*}{ VG } & $\bar{x}$ & 307.75 & 3.72 & 0.54 & 0.05 & 0.89 & 16.65 & 1.05 & 0.45 & 4.73 & 1.16 & 1.45 \\
\hline & & $\mathrm{Sd}$ & 0.48 & 0.48 & 0.21 & 0.01 & 0.01 & 0.9 & 0.01 & 0.01 & 0.09 & 0.28 & 0.42 \\
\hline \multirow{6}{*}{3} & \multirow{2}{*}{ CR } & $\bar{x}$ & 307.99 & 2.3 & 0.11 & 0.04 & 0.87 & 15.07 & 1.04 & 0.44 & 4.65 & 1.38 & 2.28 \\
\hline & & $\mathrm{sd}$ & 0.14 & 0.14 & 0.04 & 0.01 & 0.01 & 1.55 & 0.01 & 0.02 & 0.13 & 0.43 & 0.39 \\
\hline & \multirow{2}{*}{ KA } & $\bar{x}$ & 307.41 & 1.72 & -0.08 & 0 & 0.63 & 4.4 & 1.02 & 0.48 & 3.29 & 0.09 & 1.55 \\
\hline & & sd & 0.23 & 0.23 & 0.08 & 0 & 0.02 & 0.34 & 0.01 & 0.02 & 0.12 & 0.61 & 0.34 \\
\hline & \multirow{2}{*}{ VG } & $\bar{x}$ & 308.34 & 2.65 & 0.22 & 0.05 & 0.88 & 15.5 & 1.04 & 0.45 & 4.6 & 1.44 & 2.12 \\
\hline & & sd & 0.24 & 0.24 & 0.08 & 0.01 & 0.01 & 1.15 & 0.01 & 0.01 & 0.09 & 0.40 & 0.46 \\
\hline
\end{tabular}

Table A2. $p$-values (level of statistical significance: ${ }^{* *} p<0.001,{ }^{* *} p<0.01,{ }^{*} p<0.05$ ) of Tukey's HSD (Honestly Significant Difference) pairwise comparison and mean differences of treatments (CR, KA, VG) for temperature-based indices at all three Hyper-Cam LW overpasses.

\begin{tabular}{|c|c|c|c|c|}
\hline Index & Co & son & Mean Difference & $p$-Value \\
\hline \multirow{6}{*}{$T_{S}$} & 1.CR & 1.KA & 0.4 & 0.7334 \\
\hline & & 1.VG & 0.99 & $0.01 *$ \\
\hline & 2.CR & 2.KA & 0.86 & $0.04 *$ \\
\hline & & 2.VG & 0.24 & 0.9765 \\
\hline & 3.CR & 3.KA & 0.58 & 0.3081 \\
\hline & & 3.VG & 0.37 & 0.8139 \\
\hline \multirow{6}{*}{$T_{S}-T_{\text {air }}$} & 1.CR & 1.KA & 0.4 & 0.7337 \\
\hline & & 1.VG & 0.99 & $0.01 *$ \\
\hline & 2.CR & 2.KA & 0.86 & $0.04 *$ \\
\hline & & 2.VG & 0.24 & 0.9766 \\
\hline & 3.CR & 3.KA & 0.58 & 0.3085 \\
\hline & & $3 . V G$ & 0.37 & 0.8141 \\
\hline \multirow{6}{*}{ CWSI } & 1.CR & 1.KA & 0.08 & 1 \\
\hline & & $1 . \mathrm{VG}$ & 0.19 & 0.59 \\
\hline & 2.CR & 2.KA & 0.38 & $0.02 *$ \\
\hline & & 2.VG & 0.11 & 0.963 \\
\hline & 3.CR & 3.KA & 0.19 & 0.602 \\
\hline & & $3 . V G$ & 0.12 & 0.940 \\
\hline
\end{tabular}


Table A3. $p$-values (level of statistical significance: ${ }^{* * *} p<0.001,{ }^{* *} p<0.01,{ }^{*} p<0.05$ ) of Tukey's HSD pairwise comparison and mean differences of treatments (CR, KA, VG) for VNIR/SWIR based indices and $\mathrm{F}_{687}$ and $\mathrm{F}_{760}$ at three HyPlant overpasses.

\begin{tabular}{|c|c|c|c|c|}
\hline Index & Cor & son & Mean Difference & $p$-Value \\
\hline \multirow{6}{*}{ PRI } & \multirow[t]{2}{*}{ 1.CR } & 1.KA & 0.04 & $<0.001^{* * *}$ \\
\hline & & $1 . \mathrm{VG}$ & 0.01 & 0.65 \\
\hline & \multirow[t]{2}{*}{ 2.CR } & 2.KA & 0.04 & $<0.001^{* * *}$ \\
\hline & & 2.VG & 0.01 & 0.18 \\
\hline & \multirow[t]{2}{*}{ 3.CR } & 3.KA & 0.04 & $<0.001^{* * *}$ \\
\hline & & $3 . \mathrm{VG}$ & 0.01 & 0.11 \\
\hline \multirow{6}{*}{ NDVI } & \multirow[t]{2}{*}{ 1.CR } & 1.KA & 0.23 & $<0.001^{* * *}$ \\
\hline & & 1.VG & 0.01 & 0.99 \\
\hline & \multirow[t]{2}{*}{ 2.CR } & 2.KA & 0.26 & $<0.001^{* * *}$ \\
\hline & & 2.VG & 0 & 1 \\
\hline & \multirow[t]{2}{*}{ 3.CR } & 3.KA & 0.25 & $<0.001^{* * *}$ \\
\hline & & $3 . V G$ & 0 & 1 \\
\hline \multirow{6}{*}{ SR } & \multirow[t]{2}{*}{ 1.CR } & $1 . \mathrm{KA}$ & 10.9 & $<0.001^{* * *}$ \\
\hline & & 1.VG & 1.34 & 0.74 \\
\hline & \multirow{2}{*}{ 2.CR } & 2.KA & 11.74 & $<0.001^{* * *}$ \\
\hline & & 2.VG & 0.57 & 1 \\
\hline & \multirow[t]{2}{*}{ 3.CR } & 3.KA & 10.61 & $<0.001^{* * * *}$ \\
\hline & & $3 . V G$ & 0.39 & 1 \\
\hline \multirow{6}{*}{ WI } & \multirow[t]{2}{*}{ 1.CR } & 1.KA & 0.02 & $<0.01^{* *}$ \\
\hline & & 1.VG & 0 & 1 \\
\hline & \multirow[t]{2}{*}{ 2.CR } & 2.KA & 0.02 & $<0.01^{* *}$ \\
\hline & & 2.VG & 0 & 1 \\
\hline & \multirow[t]{2}{*}{ 3.CR } & 3.KA & 0.02 & $<0.01^{* *}$ \\
\hline & & 3.VG & 0 & 1 \\
\hline \multirow{6}{*}{ MSI } & \multirow[t]{2}{*}{ 1.CR } & 1.KA & 0.04 & 0.16 \\
\hline & & $1 . \mathrm{VG}$ & 0.01 & 1 \\
\hline & \multirow[t]{2}{*}{ 2.CR } & 2.KA & 0.04 & 0.04 * \\
\hline & & 2.VG & 0.02 & 0.92 \\
\hline & \multirow{2}{*}{ 3.CR } & 3.KA & 0.05 & $0.02 *$ \\
\hline & & 3.VG & 0.01 & 0.95 \\
\hline \multirow{6}{*}{ LWI } & \multirow[t]{2}{*}{ 1.CR } & 1.KA & 1.28 & $<0.001^{* * * *}$ \\
\hline & & $1 . \mathrm{VG}$ & 0 & 1 \\
\hline & 2.CR & 2.KA & 1.42 & $<0.001^{* * *}$ \\
\hline & & 2.VG & 0.02 & 1 \\
\hline & 3.CR & 3.KA & 1.36 & $<0.001^{* * * *}$ \\
\hline & & 3.VG & 0.05 & 1 \\
\hline & 1.CR & $1 . \mathrm{KA}$ & 1.02 & $<0.001^{* * *}$ \\
\hline & & $1 . \mathrm{VG}$ & 0.07 & 1 \\
\hline & 2.CR & 2.KA & 1.57 & $<0.001^{* * *}$ \\
\hline$F_{687}$ & & 2.VG & 0.28 & 0.81 \\
\hline & 3.CR & 3.KA & 1.28 & $<0.001^{* * *}$ \\
\hline & & $3 . \mathrm{VG}$ & 0.05 & 1 \\
\hline & 1.CR & $1 . \mathrm{KA}$ & 0.22 & 0.88 \\
\hline & & 1.VG & 0.24 & 0.84 \\
\hline $\mathrm{F}_{760}$ & 2.CR & 2.KA & 0.63 & $0.02 *$ \\
\hline Г760 & & 2.VG & 0.22 & 0.88 \\
\hline & 3.CR & 3.KA & 0.70 & $<0.01^{* *}$ \\
\hline & & $3 . V G$ & 0.11 & 1 \\
\hline
\end{tabular}




\section{References}

1. Mulla, D.J. Twenty five years of remote sensing in precision agriculture: Key advances and remaining knowledge gaps. Biosyst. Eng. 2013, 114, 358-371. [CrossRef]

2. Atzberger, C. Advances in Remote Sensing of Agriculture: Context Description, Existing Operational Monitoring Systems and Major Information Needs. Remote Sens. 2013, 5, 949-981. [CrossRef]

3. Yordanov, I.; Velikova, V.; Tsonev, T. Plant Responses To Drought and Stress Tolerance. Bulg. J. Plant. Phys. 2003, 38, 187-206. [CrossRef]

4. Hsiao, T.C.; Fereres, E.; Acevedo, E.; Henderson, D.W. Water Stress and Dynamics of Growth and Yield of Crop Plants. In Water and Plant Life SE-18; Lange, O.L., Kappen, L., Schulze, E.-D., Eds.; Ecological Studies; Springer: Berlin, Germany, 1976; Volume 19, pp. 281-305. ISBN 978-3-642-66431-1.

5. Jones, H.G. Irrigation scheduling: Advantages and pitfalls of plant-based methods. J. Exp. Bot. 2004, 55, 2427-2436. [CrossRef] [PubMed]

6. Cohen, Y.; Alchanatis, V.; Meron, M.; Saranga, Y.; Tsipris, J. Estimation of leaf water potential by thermal imagery and spatial analysis. J. Exp. Bot. 2005, 56, 1843-1852. [CrossRef] [PubMed]

7. Jones, H.G. Application of Thermal Imaging and Infrared Sensing in Plant Physiology and Ecophysiology. In Advances in Botanical Research; Academic Press: Cambridge, MA, USA, 2004; Volume 41, pp. 107-163.

8. Möller, M.; Alchanatis, V.; Cohen, Y.; Meron, M.; Tsipris, J.; Naor, A.; Ostrovsky, V.; Sprintsin, M.; Cohen, S. Use of thermal and visible imagery for estimating crop water status of irrigated grapevine. J. Exp. Bot. 2007, 58, 827-838. [CrossRef] [PubMed]

9. Inoue, Y.; Kimball, B.A.; Jackson, R.D.; Pinter, P.J.; Reginato, R.J. Remote estimation of leaf transpiration rate and stomatal resistance based on infrared thermometry. Agric. For. Meteorol. 1990, 51, 21-33. [CrossRef]

10. Costa, J.M.; Grant, O.M.; Chaves, M.M. Thermography to explore plant-environment interactions. J. Exp. Bot. 2013, 64, 3937-3949. [CrossRef] [PubMed]

11. Maes, W.H.; Steppe, K. Estimating evapotranspiration and drought stress with ground-based thermal remote sensing in agriculture: A review. J. Exp. Bot. 2012, 63, 4671-4712. [CrossRef] [PubMed]

12. Jackson, R.D.; Idso, S.B.; Reginato, R.J.; Pinter, P.J. Canopy temperature as a crop water stress indicator. Water Resour. Res. 1981, 17, 1133-1138. [CrossRef]

13. Rossini, M.; Panigada, C.; Cilia, C.; Meroni, M.; Busetto, L.; Cogliati, S.; Amaducci, S.; Colombo, R. Discriminating Irrigated and Rainfed Maize with Diurnal Fluorescence and Canopy Temperature Airborne Maps. ISPRS Int. J. Geo Inf. 2015, 4, 626-646. [CrossRef]

14. Panigada, C.; Rossini, M.; Meroni, M.; Cilia, C.; Busetto, L.; Amaducci, S.; Boschetti, M.; Cogliati, S.; Picchi, V.; Pinto, F.; et al. Fluorescence, PRI and canopy temperature for water stress detection in cereal crops. Int. J. Appl. Earth Obs. Geoinf. 2014, 30, 167-178. [CrossRef]

15. Zarco-Tejada, P.J.; González-Dugo, V.; Williams, L.E.; Suárez, L.; Berni, J.A.J.; Goldhamer, D.; Fereres, E. A PRI-based water stress index combining structural and chlorophyll effects: Assessment using diurnal narrow-band airborne imagery and the CWSI thermal index. Remote Sens. Environ. 2013, 138, 38-50. [CrossRef]

16. Zarco-Tejada, P.J.; González-Dugo, V.; Berni, J.A.J. Fluorescence, temperature and narrow-band indices acquired from a UAV platform for water stress detection using a micro-hyperspectral imager and a thermal camera. Remote Sens. Environ. 2012, 117, 322-337. [CrossRef]

17. Schlerf, M.; Rock, G.; Lagueux, P.; Ronellenfitsch, F.; Gerhards, M.; Hoffmann, L.; Udelhoven, T. A Hyperspectral Thermal Infrared Imaging Instrument for Natural Resources Applications. Remote Sens. 2012, 4, 3995-4009. [CrossRef]

18. Gerhards, M.; Rock, G.; Schlerf, M.; Udelhoven, T. Water stress detection in potato plants using leaf temperature, emissivity, and reflectance. Int. J. Appl. Earth Obs. Geoinf. 2016, 53, 27-39. [CrossRef]

19. Stavros, E.N.; Schimel, D.; Pavlick, R.; Serbin, S.; Swann, A.; Duncanson, L.; Fisher, J.B.; Fassnacht, F.; Ustin, S.; Dubayah, R.; et al. ISS observations offer insights into plant function. Nat. Ecol. Evol. 2017, 1. [CrossRef] [PubMed]

20. Lee, C.M.; Cable, M.L.; Hook, S.J.; Green, R.O.; Ustin, S.L.; Mandl, D.J.; Middleton, E.M. An introduction to the NASA Hyperspectral InfraRed Imager (HyspIRI) mission and preparatory activities. Remote Sens. Environ. 2015. [CrossRef] 
21. Udelhoven, T.; Schlerf, M.; Bossung, C.; Retzlaff, R.; Rock, G.; Fischer, P.; Müller, A.; Storch, T.; Segl, K.; Eisele, A.; et al. A satellite-based imaging instrumentation study for hyperspectral thermal remote sensing. Sensors 2017, 17, 1542. [CrossRef] [PubMed]

22. Hunt, E., Jr.; Rock, B. Detection of changes in leaf water content using Near- and Middle-Infrared reflectances. Remote Sens. Environ. 1989, 30, 43-54. [CrossRef]

23. Rouse, J.W.; Haas, R.H.; Deering, D.W.; Schell, J.A. Monitoring the Vernal Advancements and Retro Gradation of Natural Vegetation; Taxas A \& M University: College Station, TX, USA, 1974.

24. Gamon, J.; Peñuelas, J.; Field, C. A narrow-waveband spectral index that tracks diurnal changes in photosynthetic efficiency. Remote Sens. Environ. 1992, 41, 35-44. [CrossRef]

25. Mahajan, S.; Tuteja, N. Cold, salinity and drought stresses: An overview. Arch. Biochem. Biophys. 2005, 444, 139-58. [CrossRef] [PubMed]

26. Chaves, M.M.; Oliveira, M.M. Mechanisms underlying plant resilience to water deficits: Prospects for water-saving agriculture. J. Exp. Bot. 2004, 55, 2365-84. [CrossRef] [PubMed]

27. Suárez, L.; Zarco-Tejada, P.J.; Sepulcre-Cantó, G.; Pérez-Priego, O.; Miller, J.R.; Jiménez-Muñoz, J.C.; Sobrino, J. Assessing canopy PRI for water stress detection with diurnal airborne imagery. Remote Sens. Environ. 2008, 112, 560-575. [CrossRef]

28. Suárez, L.; Zarco-Tejada, P.J.; Berni, J.A.J.; González-Dugo, V.; Fereres, E. Modelling PRI for water stress detection using radiative transfer models. Remote Sens. Environ. 2009, 113, 730-744. [CrossRef]

29. Suárez, L.; Zarco-Tejada, P.J.; González-Dugo, V.; Berni, J.A.J.; Sagardoy, R.; Morales, F.; Fereres, E. Detecting water stress effects on fruit quality in orchards with time-series PRI airborne imagery. Remote Sens. Environ. 2010, 114, 286-298. [CrossRef]

30. Meroni, M.; Rossini, M.; Guanter, L.; Alonso, L.; Rascher, U.; Colombo, R.; Moreno, J. Remote sensing of solar-induced chlorophyll fluorescence: Review of methods and applications. Remote Sens. Environ. 2009, 113, 2037-2051. [CrossRef]

31. Porcar-Castell, A.; Tyystjarvi, E.; Atherton, J.; van der Tol, C.; Flexas, J.; Pfundel, E.E.; Moreno, J.; Frankenberg, C.; Berry, J.A. Linking chlorophyll a fluorescence to photosynthesis for remote sensing applications: Mechanisms and challenges. J. Exp. Bot. 2014, 65, 4065-4095. [CrossRef] [PubMed]

32. Rossini, M.; Nedbal, L.; Guanter, L.; Ač, A.; Alonso, L.; Burkart, A.; Cogliati, S.; Colombo, R.; Damm, A.; Drusch, M.; et al. Red and far red Sun-induced chlorophyll fluorescence as a measure of plant photosynthesis. Geophys. Res. Lett. 2015, 42, 1632-1639. [CrossRef]

33. Rascher, U.; Alonso, L.; Burkart, A.; Cilia, C.; Cogliati, S.; Colombo, R.; Damm, A.; Drusch, M.; Guanter, L.; Hanus, J.; et al. Sun-induced fluorescence-A new probe of photosynthesis: First maps from the imaging spectrometer HyPlant. Glob. Chang. Biol. 2015, 21, 4673-4684. [CrossRef] [PubMed]

34. Francini, A.; Lorenzini, G.; Nali, C. The antitranspirant Di-1-p-menthene, a potential chemical protectant of ozone damage to plants. Water Air Soil Pollut. 2011, 219, 459-472. [CrossRef]

35. Mikiciuk, G.; Mikiciuk, M.; Ptak, P. The Effects of Anitranspirant Di-1-P-Menthene on Some Physiological Traits of Strawberry. J. Ecol. Eng. 2015, 16, 161-167. [CrossRef]

36. Ouerghi, F.; Ben-Hammouda, M.; Teixeira Da Silva, J.A.; Albouchi, A.; Bouzaien, G.; Aloui, S.; Cheikh-M'hamed, H.; Nasraoui, B. The Effects of Vapor Gard on some Physiological Traits of Durum Wheat and Barley Leaves under Water Stress. Agric. Conspec. Sci. 2015, 79, 261-267.

37. Plaut, Z.; Magril, Y.; Kedem, U. A new film forming material, which reduces water vapour conductance more than $\mathrm{CO}_{2}$ fixation in several horticultural crops. J. Hortic. Sci. Biotechnol. 2004, 79, 528-532. [CrossRef]

38. Kahle, A.B.; Alley, R.E. Separation of temperature and emittance in remotely sensed radiance measurements. Remote Sens. Environ. 1992, 42, 107-111. [CrossRef]

39. Buitrago, M.F.; Groen, T.A.; Hecker, C.A.; Skidmore, A.K. Changes in thermal infrared spectra of plants caused by temperature and water stress. ISPRS J. Photogramm. Remote Sens. 2016, 111, 22-31. [CrossRef]

40. Rock, G.; Gerhards, M.; Schlerf, M.; Hecker, C.; Udelhoven, T. Plant species discrimination using emissive thermal infrared imaging spectroscopy. Int. J. Appl. Earth Obs. Geoinf. 2016, 53, 16-26. [CrossRef]

41. Salisbury, J.W.; D'Aria, D.M. Emissivity of terrestrial materials in the $8-14 \mu \mathrm{m}$ atmospheric window. Remote Sens. Environ. 1992, 42, 83-106. [CrossRef]

42. Lourakis, M.I.A. A Brief Description of the Levenberg-Marquardt Algorithm Implemened by Levmar. Available online: http:/ / users.ics.forth.gr/lourakis/levmar/levmar.pdf (accessed on 20 March 2017). 
43. Jackson, R.D.; Reginato, R.J.; Idso, S.B. Wheat canopy temperature: A practical tool for evaluating water requirements. Water Resour. Res. 1977, 13, 651-656. [CrossRef]

44. Jones, H.G. Use of infrared thermometry for estimation of stomatal conductance as a possible aid to irrigation scheduling. Agric. For. Meteorol. 1999, 95, 139-149. [CrossRef]

45. Gonzalez-Dugo, V.; Zarco-Tejada, P.; Nicolás, E.; Nortes, P.A.; Alarcón, J.J.; Intrigliolo, D.S.; Fereres, E. Using high resolution UAV thermal imagery to assess the variability in the water status of five fruit tree species within a commercial orchard. Precis. Agric. 2013, 14, 660-678. [CrossRef]

46. Meron, M.; Tsipris, J.; Charitt, D. Remote mapping of crop water status to assess spatial variability of crop stress. In Precision Agriculture; Stafford, J., Werner, A., Eds.; Wageningen Academic Publishers: Wageningen, The Netherlands, 2003; ISBN 978-90-76998-21-3.

47. Maier, S.W.; Günther, K.P.; Stellmes, M. Sun-Induced Fluorescence: A New Tool for Precision Farming. In Digital Imaging and Spectral Techniques: Applications to Precision Agriculture and Crop Physiology; Schepers, J., VanToai, T., Eds.; American Society of Agronomy; Crop Science Society of America; Soil Science Society of America: Madison, WI, USA, 2003; pp. 209-222.

48. Alonso, L.; Gomez-Chova, L.; Vila-Frances, J.; Amoros-Lopez, J.; Guanter, L.; Calpe, J.; Moreno, J. Improved Fraunhofer Line Discrimination Method for Vegetation Fluorescence Quantification. IEEE Geosci. Remote Sens. Lett. 2008, 5, 620-624. [CrossRef]

49. Berk, A.; Anderson, G.P.; Acharya, P.K.; Bernstein, L.S.; Muratov, L.; Lee, J.; Fox, M.; Adler-Golden, S.M.; Chetwynd, J.H.; Hoke, M.L.; et al. MODTRAN 5: A reformulated atmospheric band model with auxiliary species and practical multiple scattering options: Update. In Remote Sensing of Clouds and the Atmosphere IX; Shen, S.S., Lewis, P.E., Eds.; International Society for Optics and Photonics: Bellingham, WA, USA, 2005; pp. 78-85.

50. Verhoef, W.; Bach, H. Simulation of hyperspectral and directional radiance images using coupled biophysical and atmospheric radiative transfer models. Remote Sens. Environ. 2003, 87, 23-41. [CrossRef]

51. Wieneke, S.; Ahrends, H.; Damm, A.; Pinto, F.; Stadler, A.; Rossini, M.; Rascher, U. Airborne based spectroscopy of red and far-red sun-induced chlorophyll fluorescence: Implications for improved estimates of gross primary productivity. Remote Sens. Environ. 2016, 184, 654-667. [CrossRef]

52. Peñuelas, J.; Filella, I.; Biel, C.; Serrano, L.; Savé, R. The reflectance at the $950-970 \mathrm{~nm}$ region as an indicator of plant water status. Int. J. Remote Sens. 1993, 14, 1887-1905. [CrossRef]

53. Seelig, H.-D.; Hoehn, A.; Stodieck, L.S.; Klaus, D.M.; Adams, W.W.; Emery, W.J. Relations of remote sensing leaf water indices to leaf water thickness in cowpea, bean, and sugarbeet plants. Remote Sens. Environ. 2008, 112, 445-455. [CrossRef]

54. Jordan, C.F. Derivation of Leaf-Area Index from Quality of Light on the Forest Floor. Ecology 1969, 50, 663-666. [CrossRef]

55. Struthers, R.; Ivanova, A.; Tits, L.; Swennen, R.; Coppin, P. Thermal infrared imaging of the temporal variability in stomatal conductance for fruit trees. Int. J. Appl. Earth Obs. Geoinf. 2015, 39, 9-17. [CrossRef]

56. Juszczak, R.; Humphreys, E.; Acosta, M.; Michalak-Galczewska, M.; Kayzer, D.; Olejnik, J. Ecosystem respiration in a heterogeneous temperate peatland and its sensitivity to peat temperature and water table depth. Plant Soil 2013, 366, 505-520. [CrossRef]

57. Chojnicki, B.H.; Michalak, M.; Acosta, M.; Juszczak, R.; Augustin, J.; Drösler, M.; Olejnik, J. Measurements of Carbon Dioxide Fluxes by Chamber Method at the Rzecin Wetland Ecosystem, Poland. Pol. J. Environ. Stud. 2010, 19, 283-291.

58. Acosta, M.; Juszczak, R.; Chojnicki, B.; Pavelka, M.; Havránková, K.; Lesny, J.; Krupková, L.; Urbaniak, M.; Machačová, K.; Olejnik, J. $\mathrm{CO}_{2}$ Fluxes from Different Vegetation Communities on a Peatland Ecosystem. Wetlands 2017. [CrossRef]

59. Hoffmann, M.; Jurisch, N.; Albiac Borraz, E.; Hagemann, U.; Drösler, M.; Sommer, M.; Augustin, J. Automated modeling of ecosystem $\mathrm{CO} 2$ fluxes based on periodic closed chamber measurements: A standardized conceptual and practical approach. Agric. For. Meteorol. 2015, 200, 30-45. [CrossRef]

60. R Core Team R: A Language and Environment for Statistical Computing. Available online: https://www.rproject.org/ (accessed on 17 July 2018).

61. Pinheiro, J.; Bates, D.; DebRoy, S.; Sarkar, D.; Team, R.C. Nlme: Linear and Nonlinear Mixed Effects Models. Available online: https:/ / ci.nii.ac.jp/naid/10025451956/ (accessed on 17 July 2018).

62. Lenth, R. V Least-Squares Means: The $\{R\}$ Package \{lsmeans\}. J. Stat. Softw. 2016, 69, 1-33. [CrossRef] 
63. Sobrino, J.A.; Jiménez-Muñoz, J.C.; Zarco-Tejada, P.J.; Sepulcre-Cantó, G.; de Miguel, E. Land surface temperature derived from airborne hyperspectral scanner thermal infrared data. Remote Sens. Environ. 2006, 102, 99-115. [CrossRef]

64. Nilsson, H.E. Hand-held radiometry and IR-thermography of plant diseases in field plot experiments. Int. J. Remote Sens. 1991, 12, 545-557. [CrossRef]

65. Chiwaki, K.; Nagamori, S.; Inoue, Y. Predicting bacterial wilt disease of tomato plants using remotely sensed thermal imagery. J. Agric. Meteorol. 2005, 61, 153-0164. [CrossRef]

66. Jacquemoud, S.; Verhoef, W.; Baret, F.; Bacour, C.; Zarco-Tejada, P.J.; Asner, G.P.; François, C.; Ustin, S.L. PROSPECT + SAIL models: A review of use for vegetation characterization. Remote Sens. Environ. 2009, 113, S56-S66. [CrossRef]

67. Ashourloo, D.; Mobasheri, M.R.; Huete, A. Evaluating the effect of different wheat rust disease symptoms on vegetation indices using hyperspectral measurements. Remote Sens. 2014, 6, 5107-5123. [CrossRef]

68. Verrelst, J.; van der Tol, C.; Magnani, F.; Sabater, N.; Rivera, J.P.; Mohammed, G.; Moreno, J. Evaluating the predictive power of sun-induced chlorophyll fluorescence to estimate net photosynthesis of vegetation canopies: A SCOPE modeling study. Remote Sens. Environ. 2016, 176, 139-151. [CrossRef]

(C) 2018 by the authors. Licensee MDPI, Basel, Switzerland. This article is an open access article distributed under the terms and conditions of the Creative Commons Attribution (CC BY) license (http:/ / creativecommons.org/licenses/by/4.0/). 